Review

\title{
Risk Factors Contributing to Type 2 Diabetes and Recent Advances in the Treatment and Prevention
}

\author{
Yanling $\mathrm{Wu}^{1,2}$, Yanping Ding ${ }^{1,2}$, Yoshimasa Tanaka ${ }^{3}$ and Wen Zhang ${ }^{2 \bowtie}$ \\ 1. Lab of Molecular Immunology, Zhejiang Provincial Center for Disease Control and Prevention, 3399 Binsheng Road, Hangzhou, 310051 , \\ China; \\ 2. Lab of Chemical Biology and Molecular Drug Design, College of Pharmaceutical Science, Zhejiang University of Technology, 18 \\ Chaowang Road, Hangzhou, 310014, China; \\ 3. Center for Innovation in Immunoregulative Technology and Therapeutics, Graduate School of Medicine, Kyoto University, Kyoto, \\ 606-8501, Japan.
}

\begin{abstract}
$\triangle$ Corresponding author: Yanling Wu, Lab of Molecular Immunology, Virus Inspection Department of Zhejiang Provincial Center for Disease Control and Prevention, 3399 Binsheng Road, Hangzhou, 310051, PR China; Tel: +86-571-87115282; Fax: +86-571-87115282; e-mail: ylwu@cdc.zj.cn. Wen Zhang, Lab of Chemical Biology and Molecular Drug Design, College of Pharmaceutical Science, Zhejiang University of Technology, 18 Chaowang Road, Hangzhou, 310014, PR China; Tel: +86-571-88871507; Fax: +86-571-88871507; e-mail: wzhang63@zjut.edu.cn.
\end{abstract}

(c) Ivyspring International Publisher. This is an open-access article distributed under the terms of the Creative Commons License (http://creativecommons.org/ licenses/by-nc-nd/3.0/). Reproduction is permitted for personal, noncommercial use, provided that the article is in whole, unmodified, and properly cited.

Received: 2014.06.28; Accepted: 2014.08.0I; Published: 2014.09.06

\begin{abstract}
Type 2 diabetes is a serious and common chronic disease resulting from a complex inheritance-environment interaction along with other risk factors such as obesity and sedentary lifestyle. Type 2 diabetes and its complications constitute a major worldwide public health problem, affecting almost all populations in both developed and developing countries with high rates of diabetes-related morbidity and mortality. The prevalence of type 2 diabetes has been increasing exponentially, and a high prevalence rate has been observed in developing countries and in populations undergoing "westernization" or modernization. Multiple risk factors of diabetes, delayed diagnosis until micro- and macro-vascular complications arise, life-threatening complications, failure of the current therapies, and financial costs for the treatment of this disease, make it necessary to develop new efficient therapy strategies and appropriate prevention measures for the control of type 2 diabetes. Herein, we summarize our current understanding about the epidemiology of type 2 diabetes, the roles of genes, lifestyle and other factors contributing to rapid increase in the incidence of type 2 diabetes. The core aims are to bring forward the new therapy strategies and cost-effective intervention trials of type 2 diabetes.
\end{abstract}

Key words: type 2 diabetes, genetic factor, lifestyle, treatment, intervention trial.

\section{Introduction}

Diabetes mellitus (DM) is characterized by chronic hyperglycemia and impaired carbohydrates, lipids, and proteins metabolism caused by complete or partial insufficiency of insulin secretion and/or insulin action. There are two primary forms of diabetes, insulin-dependent diabetes mellitus (type 1 diabetes mellitus, T1DM) and non-insulin-dependent diabetes mellitus (type 2 diabetes mellitus, T2DM). T2DM is the most common form of DM, which accounts for $90 \%$ to $95 \%$ of all diabetic patients [1] and is expected to increase to 439 million by 2030 [2]. In
China, the latest statistical data show that diabetes and pre-diabetes are prevalent among people older than 20 -year-old, with the percentages being $9.7 \%$ and $15.5 \%$ for T1DM and T2DM, respectively [3]. T2DM mostly results from the interaction among genetic, environmental and other risk factors. Furthermore, loss of first-phase of insulin release, abnormal pulsatility of basal insulin secretion, and increased glucagon secretion also accelerate the development of T2DM [4, 5]. Although T2DM patients are generally independent of exogenous insulin, they may need it 
when blood glucose levels are not well controlled with diet alone or with oral hypoglycemic drugs. In addition, people with T2DM are often accompanied by complications, such as cardiovascular diseases, diabetic neuropathy, nephropathy, and retinopathy. Diabetes and its associated complications lower the quality of people's lives and generate enormous economic and social burdens [6].

\section{Epidemiology}

T2DM has become an observably global public health problem. Analysis of recent statistical data reveals that T2DM has several new epidemiological characteristics. Firstly, diabetes keeps a steady increase in developed countries, such as United States and Japan. And it is worthy of note that T2DM has become a serious issue at an alarming rate in developing countries. It is predicted that T2DM will continue to increase in the next twenty years, and more than $70 \%$ of the patients will appear in developing countries, with the majority of them being 45-64 years old [7]. Even today, seven out of top ten countries with the largest number of diabetes patients are lowor middle-income countries, including India, China, Russia, Brazil, Pakistan, Indonesia, and Bangladesh [7], among which the prevalence rates are $12.1 \%$ and $9.7 \%$ in India and China, respectively $[8,9]$. Secondly, although advancing age is a risk factor for T2DM, rising rates of childhood obesity have resulted in T2DM becoming more common in children, teenagers and adolescents, which is a serious emerging of the epidemic and a new public health problem of significant proportions [10].

\section{Correlations with and influencing factors on T2DM}

Heritable genetic correlation. Genetic component: Although we have not completely elucidated the pathophysiology of T2DM so far, it is the case that the disease has a major genetic component. Higher concordance rates are found among monozygotic (96\%) than dizygotic (DZ) twins in some $[11,12]$ but not all [13] twin studies, which has been a compelling evidence of a significant genetic component in T2DM. Moreover, $40 \%$ of first-degree relatives of T2DM patients may develop diabetes, whereas the incident rate is only $6 \%$ in the general population [14].

Susceptibility loci: In addition to a considerable number of genetic components associated with T2DM, segregation analysis also suggests the polygenic nature of T2DM. The susceptibility loci of T2DM have been discovered by genome-wide association studies (GWAS) since early 2007 [15-21]. Then, numerous GWAS conducted in different countries and ethnic groups have reported linkage signals at the same or different chromosomes with T2DM, and have successfully identified approximately 75 susceptibility loci related to T2DM. Examples of candidate genes are KCNJ11 (potassium inwardly rectifying channel, subfamily J, member 11), TCF7L2 (transcription factor 7-like 2, the strongest T2D locus identified to date), IRS1 (insulin receptor substrate 1), MTNR1B (melatonin-receptor gene), PPARG2 (peroxisome proliferator-activated receptor gamma 2), IGF2BP2 (insulin-like growth factor two binding protein 2), CDKN2A (cyclin-dependent kinase inhibitor 2A), HHEX (hematopoietically expressed homeobox) and FTO (fat mass and obesity associated) gene. van Exel and his group found that low IL-10 production capacity is also associated with T2DM [22]. It is worth highlighting that IL-10-1082A/G polymorphism is associated with T2DM susceptibility in Asians, but not in Europeans and Africans, which may be ascribable to various genetic background and environmental exposures [23]. Some important susceptibility loci are listed in Table 1.

Table I. Susceptibility loci associated with T2DM discovered with GWAS.

\begin{tabular}{|c|c|c|c|c|c|}
\hline Gene & Gene Region & SNPs & Population & P-Value & Ref. \\
\hline \multirow[t]{4}{*}{ KCNQ1 } & 11p15.4 & rs2237897 & Japanese & $6.8 \times 10^{-13}$ & [24] \\
\hline & 11p15.4 & rs2237895 & Chinese & $9.7 \times 10^{-10}$ & [25] \\
\hline & 11p15.4 & rs231362 & European & $2.8 \times 10^{-13}$ & [26] \\
\hline & 11p15.4 & rs2237892 & Japanese & $1.7 \times 10^{-42}$ & [27] \\
\hline TCF7L2 & $10 q 25.2$ & rs7903146 & European & $2.0 \times 10^{-31}$ & [18] \\
\hline \multirow[t]{2}{*}{ KCNJ11 } & 11p15.1 & rs5219 & European & $6.7 \times 10^{-11}$ & [17] \\
\hline & 11p15.1 & rs5215 & UK & $5.0 \times 10^{-11}$ & [19] \\
\hline IRS1 & $2 \mathrm{q} 36.3$ & rs7578326 & European & $5.4 \times 10^{-20}$ & [26] \\
\hline MTNR1B & 11q14.3 & rs1387153 & European & $7.8 \times 10^{-15}$ & [26] \\
\hline \multirow[t]{2}{*}{ IGF2BP2 } & $3 q 27.2$ & rs4402960 & European & $8.9 \times 10^{-16}$ & [17] \\
\hline & $3 q 27.2$ & rs6769511 & European & $9.0 \times 10^{-16}$ & {$[19,24]$} \\
\hline \multirow[t]{3}{*}{ CDKN2A/B } & 9 p21.3 & rs564398 & UK & $1.3 \times 10^{-6}$ & [19] \\
\hline & $9 p 21.3$ & rs2383208 & Japanese & $1.6 \times 10^{-7}$ & [28] \\
\hline & 9 p21.3 & rs10811661 & European & $7.8 \times 10^{-15}$ & [17] \\
\hline \multirow[t]{2}{*}{ HHEX } & $10 \mathrm{q} 23.33$ & rs1111875 & European & $5.7 \times 10^{-10}$ & [17] \\
\hline & $10 \mathrm{q} 23.33$ & rs5015480 & European & $1.0 \times 10^{-15}$ & [29] \\
\hline \multirow[t]{2}{*}{ PPARG2 } & $3 p 25.2$ & rs1801282 & European & $1.7 \times 10^{-6}$ & [17] \\
\hline & $3 p 25.2$ & rs17036101 & European & $7.5 \times 10^{-6}$ & [30] \\
\hline
\end{tabular}

Among these susceptible loci, KCNJ11 encodes the islet ATP-sensitive potassium channel Kir6.2; TCF7L2 regulates proglucagon gene expression and produces glucagon-like peptide 1[31]; IRS1 has an effect on insulin action [32]; MTNR1B is correlated with endogenous ligand melatonin that mediates circadian rhythm and affects metabolic regulation [33]; PPARG2 encodes a transcription factor for adipocyte differentiation [34]; IGF2BP2 is involved in pancreas development, growth and stimulation of insulin action [34]; HHEX affects $\beta$ cell development; and FTO predisposes to diabetes through acting on BMI (Body Mass Index) [35]. Meanwhile, many of these loci are 
also therapeutic targets for the extensively used pharmaceuticals of T2DM, for example, KCNJ11 and PPARG2 are targets of sulphonylurea and thiazolidinedione classes of drugs widely used for the treatment of T2DM, respectively [36, 37]. Nevertheless, there are still many unsorted loci for the T2DM pathogenesis. We thus need to expand our current biological knowledge to completely understand and control T2DM.

Lifestyle factor correlation. A wide variety of lifestyle factors are also of great importance to the development of T2DM, such as sedentary lifestyle [38], physical inactivity [39], smoking [40] and alcohol consumption [41]. Substantial epidemiological studies have shown that obesity is the most important risk factor for T2DM, which may influence the development of insulin resistance and disease progression [42]. Nearly $90 \%$ of diabetic patients develop T2DM mostly relating to excess body weight according to the World Health Organization (WHO, 2011). Furthermore, obesity is strongly inherited [43]. Pamidi et al. demonstrated that obstructive sleep apnea (OSA), a treatable sleep disorder that is pervasive among overweight and obese adults, has become a novel, modifiable risk factor relevant to insulin resistance and glucose intolerance, and may influence on the development of prediabetes $(20 \%-67 \%)$ and T2DM (15\%-30\%), independent of shared risk factors [44-46]. Several studies have indicated that OSA in T2DM patients is much more prevalent $(36 \%-60 \%)$ than in the general population $[47,48]$.

In addition, diet is considered as a modifiable risk factor for T2DM. Studies have shown that a low-fiber diet with a high glycemic index is positively associated with a higher risk of T2DM [49], and specific dietary fatty acids may affect insulin resistance and the risk of diabetes in varying degrees [50]. Total and saturated fat intake is associated with an increased risk of T2DM independently of BMI, but higher intake of linoleic acid has the opposite effect, especially among leaner and younger men [51]. Frequent consumption of processed meat, but not other meats, may increase the risk of T2DM after adjustment for BMI, prior weight change, and alcohol and energy intake [51]. Soft drinks have also been bounded up with increased risk of T2DM [52] and metabolic syndrome [53], because they are directly associated with BMI [54].

Gut metagenome correlation. In some recent studies, gut metagenome was shown to be a factor for the development of T2DM [55]. Different kinds of gut bacteria may play different roles in maintaining or interacting with their environment. Two-stage metagenome-wide association study (MGWAS) suggested that T2DM patients show a moderate degree of gut microbial dysbiosis, with various butyrate-producing bacteria being decreased (Clostridiales sp. SS3/4, Roseburia intestinalis, Roseburia inulinivorans, Eubacterium rectale and Faecalibacterium prausnitzii) and some opportunistic pathogens being increased (Bacteroides caccae, Clostridium hathewayi, Clostridium ramosum, Clostridium symbiosum, Eggerthella lenta and Escherichia coli) $[56,57]$.

In T2DM patients, the gut microbiota presents enrichment in membrane transport of sugars, methane metabolism, branched-chain amino acid (BCAA) transport, xenobiotics degradation and metabolism, and sulphate reduction; and reduction in the level of bacterial chemotaxis, flagellar assembly, butyrate biosynthesis and metabolism of cofactors and vitamins. A study showed that seven of the T2DM-enriched KEGG orthologues markers were associated with oxidative stress resistance, including nitric oxide reductase (K02448), putative iron-dependent peroxidase (K07223), cytochrome $c$ peroxidase (K00428), catalase (K03781), peroxiredoxin (K03386), Mn-containing catalase (K07217), and glutathione reductase (NADPH) (K00383), which were not seen in control-enriched KEGG orthologues markers [58]. In addition, it was found that 14 KEGG orthologues markers, which were markedly up-regulated in T2DM patients, were related to drug resistance. These results demonstrated that T2DM patients may have a more hostile gut environment that stimulates defense mechanisms against microbes and oxidative stresses.

There is a T2D classifier system based on gut microbiota, in which the T2DM index is correlated with the ratio of T2DM patients and this system provides accurate classification of T2D individuals [58]. For example, butyrate-producing bacteria may play a protective role against several types of diseases, and dysbiosis in T2DM patients may result from 'functional dysbiosis' rather than a specific microbial species.

Gut metagenomic markers show higher specificity for differentiation between T2DM cases and controls based on human genome variation, which may be a promising complementary approach to monitor gut health for risk assessment of this disease [59].

Vitamins and type 2 Diabetes. Vitamin D: Accumulating evidence supports that vitamin $\mathrm{D}$ may have a potential role in the control of T2DM [60,61], as seasonal variation is found in glycemic status of T2DM patients, in which hypovitaminosis D frequently occurred in the winter is likely to be associated with the aggravation of T2DM. A recent research shows that vitamin D deficiency may have negative effects on glucose intolerance, insulin secretion and T2DM [62], either directly via vitamin D receptor 
(VDR) activation or indirectly via calcemic hormones and also via inflammation [63, 64]. As both 1-a-hydroxylase and VDR are present in pancreatic $\beta$ cells, vitamin D has significant roles in the synthesis and release of insulin [65]. Furthermore, vitamin D has influence on the insulin sensitivity by controlling calcium flux through the membrane in both $\beta$ cells and peripheral insulin-target tissues [66]. In addition, vitamin D supplementation is recognized as a promising and inexpensive therapy, which may decrease the risk of T2DM and improve glycemic parameters in T2DM patients [67]. Therefore, it is seemingly that the positive effects of vitamin D are correlated with its action on insulin secretion and sensitivity as well as on inflammation.

Vitamin K: Vitamin K has two naturally occurring forms, including phylloquinone (vitamin K1) and menaquinones. Menaquinone-4 (vitamin K2) is considered as the active form of vitamin $\mathrm{K}$ in the bone tissue and functions in maintaining bone quality [68] and also as a transcriptional regulator of bone-specific genes that acts through steroid and xenobiotic receptors (SXRs) to promote expression of osteoblastic markers [69]. It plays a protective role in bone fractures, in which the substance can promote $\gamma$-carboxylation of osteocalcin and induce production and secretion of osteocalcin by osteoblasts or may

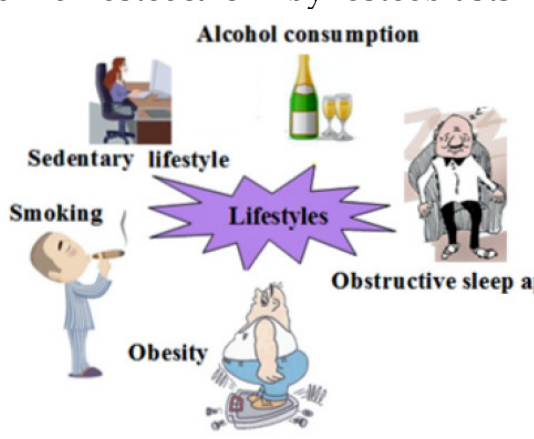

(A)

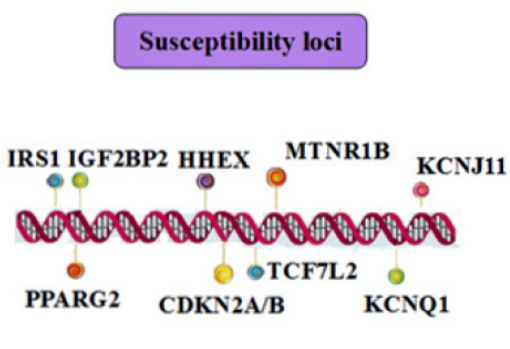

(B)

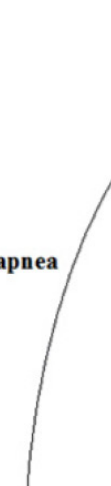

stimulate bone formation through SXRs.

Besides, a recent survey indicates that vitamin $\mathrm{K} 1$ provides benefits in glucose homeostasis, as higher intake of vitamin $\mathrm{K} 1$ is correlated with greater insulin sensitivity and glycemic status [70]. Because poor glycemic control and bone quality may occur when vitamin $K$ is deficient, it is cardinal to exclude vitamin $\mathrm{K}$ deficiency in T2DM patients. Several preclinical and clinical observations show that vitamin K2 has effects on bone quality and subsequent bone mechanical strength in T2DM patients independently of increasing BMD (bone mineral density) [71, 72]. It is also suggested that vitamin K2 may improve osteocyte density and lacunar occupancy by viable osteocytes in the cortical bone of glucocorticoid-treated or sciatic neurectomized rats [73, 74]. In addition, vitamin K2 may down-regulate bone turnover and stimulate lamellar bone formation, and prevent an increase in bone resorption with maintaince of bone formation and prevent a decrease in lamellar bone formation in glucocorticoid-treated rats [75]. Further studies are required for the comprehensive assessment of the role of vitamin $\mathrm{K}$ in the development of T2DM.

In summary, the above-mentioned susceptibility loci and other influencing factors of T2DM are shown in Figure 1.

\section{Mechanism}

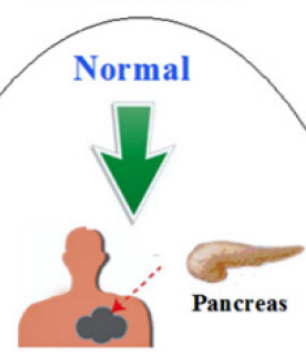

Insulin Resistance

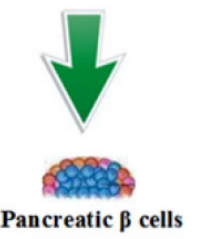

Pancreatic $\beta$ cells

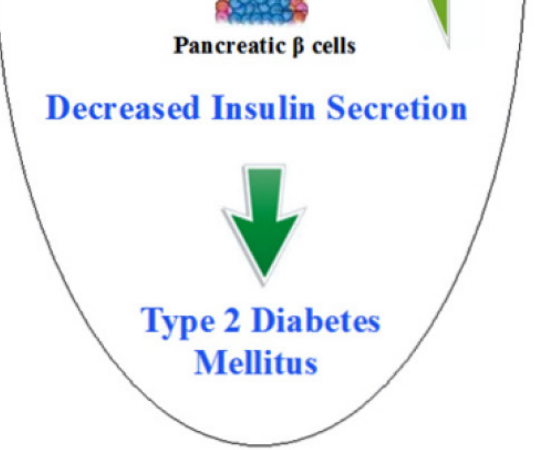

(E)

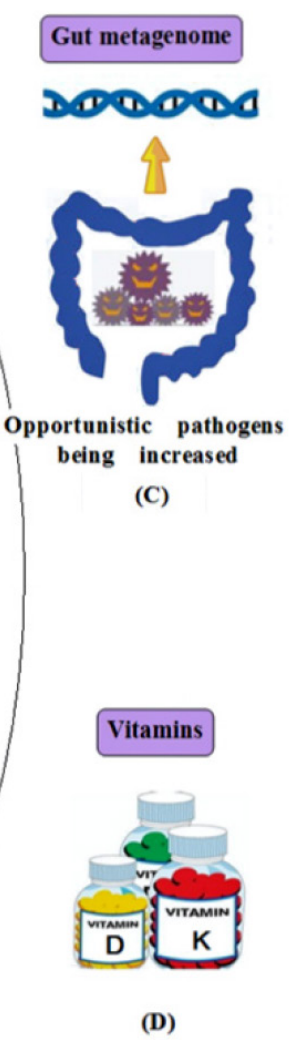

(D)

Figure I. A summary of the influencing factors and mechanism of T2DM. (A) Lifestyles; (B) Susceptibility loci; (C) Gut metagenome association; (D) Vitamins. (E) The mechanism of T2DM. 


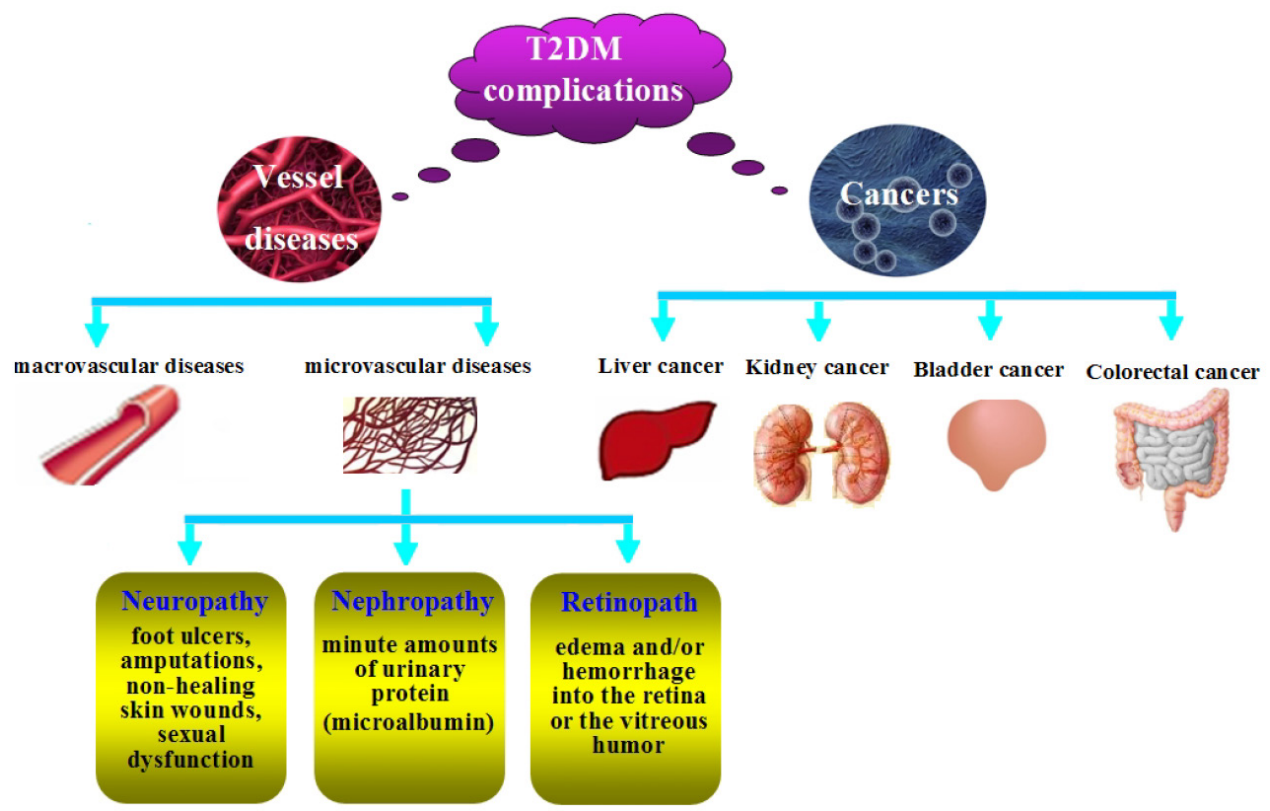

Figure 2. The complications of T2DM.

\section{Complications}

T2DM patients are more susceptible to different forms of both short- and long-term complications. As shown in Figure 2, the complications include macrovascular diseases (hypertension, hyperlipidemia, heart attacks, coronary artery disease, strokes, cerebral vascular disease, and peripheral vascular disease), microvascular diseases (retinopathy, nephropathy, and neuropathy) and cancers.

Cardiovascular disease. Cardiovascular disease is a primary cause of mortality and morbidity in both prediabetes and T2DM, the potential mechanism for which is oxidative stress that has important effects on atherogenesis and may contribute to low-density lipoprotein (LDL) oxidation [76]. Prevention of premature cardiovascular events involves complex interactive treatments with antihypertensives, lipid-lowering agents, and routine low-dose aspirin administration [77].

Diabetic neuropathy. Diabetic neuropathy may be associated with foot ulcers, amputations, non-healing skin wounds, and sexual dysfunction [12]. The neuropathy results in loss of protective sensation in the feet, which leads to callous formation, ulceration and other injury, and may also result in the infection of the skin (e.g. cellulitis) and/or bones of the foot (e.g. osteomyelitis) and gangrene [77]. Sexual dysfunction usually occurs in young-aged diabetic patients because of oxidative stress in cavernous tissues [78].

Diabetic nephropathy. Diabetic nephropathy is one of the most important microvascular complica- tions, whose earliest manifestation is the presence of minute amounts of urinary protein (microalbumin) which can not be detected in routine urinalysis, but is detectable by specific testing. If the detection can be done in the earlier phase, the progression of nephropathy can be prevented. This is, however, frequently overlooked because of the unawareness that the routine urinalysis lacks sensitivity in detecting microalbuminuria [77].

Diabetic retinopath. The retina is the most vascular region in the body, as it needs high oxygen to convert light into electrical energy in the rods and cones. Chronic hyperglycemia may cause microvascular damage to the retinal vessels, resulting in edema and/or hemorrhage into the retina or the vitreous humor because of vascular permeability. In fact, dysglycemia often occurs earlier than the diagnosis of diabetes patients, because nearly $20 \%$ of newly diagnosed diabetes patients show evidence of retinopathy [79].

Cancers. Epidemiologic evidence has demonstrated that diabetes may elevate the risk of cancer such as colorectal cancer [80], liver cancer [81], bladder cancer [82], breast cancer [83], kidney cancer [84], which varies depending on the subsites of specific cancers. Mechanisms underlying the association of T2DM with cancer risk are as follows: firstly, T2DM and cancers usually share many risk factors such as age, obesity, sedentary lifestyle, smoking, higher intake of saturated fats and refined carbohydrates, and some psychology factors [85]. Secondly, hyperinsulinemia is one of the major characteristics of T2DM. Meanwhile, it might promote carcinogenesis directly [86] as it may promote the proliferation of colonic 
tumors in vitro and in experimental animals [87]. Besides, hyperinsulinemia may increase the level of IGF-1 which has mitogenic and antiapoptotic actions on cancer cells [88], and the plasma or serum level of IGF-1 is also positively correlated with the risk of cancers $[89,90]$.

\section{Treatment of T2DM}

Common non-insulin antidiabetic drugs. Biguanides: Biguanides are one of the major classes of antidiabetic drugs, among which metformin is the most common drug used in the first line therapy for diabetes mellitus [91]. Metformin has been proven to be efficacious in lowering blood glucose, increasing insulin sensitivity, reducing cardiovascular [92] and hypoglycemia risk [93], and is the only hypoglycemic agent to improve macrovascular outcomes [94] and to reduce mortality rates in $\mathrm{T} 2 \mathrm{DM}$ patients [95]. The glucose-lowering effect of metformin is mainly through reducing hepatic glucose output such as gluconeogenesis and glycogenolysis, and increasing insulin-stimulated glucose uptake and glycogenesis in skeletal muscle [96]. In addition, it is demonstrated that metformin has important roles in activating AMP-activated protein kinase (AMPK) which acts on the expression of hepatic gluconeogenic genes [97] and decreasing progression of impaired glucose tolerance in T2DM patients [98]. It is worthy of note that metformin should be used cautiously in elderly diabetic patients owing to the concern of lactic acidosis, gastrointestinal (GI) effects such as nausea, vomiting diarrhea and flatulence, the reduction of calorie intake, and weight loss. Besides, metformin should not be used in patients with chronic or acute renal insufficiency, and must be terminated when creatinine levels reach $1.4 \mathrm{mg} / \mathrm{dL}(120 \mu \mathrm{mol} / \mathrm{L})$ in women or 1.5 $\mathrm{mg} / \mathrm{dL}(130 \mu \mathrm{mol} / \mathrm{L})$ in men [99].

Sulfonylureas: Sulphonylureas are second line agents widely used in the treatment of T2DM patients who are not severely obese, which act directly on the islet $\beta$ cells to close ATP-sensitive $\mathrm{K}^{+}$channels and stimulate insulin secretion [100]. They remain effective until they reach their targets when used alone or combined with other anti-hyperglycemic drugs [1], but they are dependent on the presence of enough $\beta$ cells with sufficient functional reserve. The major acute adverse reaction of sulphonylureas is higher rate of hypoglycemia [101], especially in older adults with impaired renal function, hepatic dysfunction, and those with poor oral intake, or alcohol abuse, or caloric restriction and so on [102]. Sulphonylurea-induced hypoglycemia may be exacerbated by interaction with a variety of drugs, such as aspirin, oxidase inhibitors, and phenylbutazone [1]. In addition, sulfonylureas can cause weight gain. The use of sulfonylureas, however, seems to have no obvious influence on cardiovascular diseases [103].

Thiazolidinediones: Thiazolidinediones (TZDs) are a class of insulin sensitizers, including troglitazone, rosiglitazone, and pioglitazone. They are peroxisome proliferator-activated receptor $\gamma$ (PPAR- $\gamma$ ) ligands which control normal skeletal muscle and hepatic insulin sensitivity [104]. The TZDs have more durable action to regulate hyperglycemia than sulfonylureas and metformin, and do not increase the risk of hypoglycemia when used as monotherapy [1]. TZDs are efficacious in combined therapy with other classes of antidiabetic agents, especially in combination with insulin to reduce the high insulin dosage and improve glycemic control in T2DM [1]. Moreover, preliminary clinical studies have demonstrated that TZDs and metformin, two different classes of drugs, can be used together to cooperatively lower blood glucose activity [1]. However, TZDs exhibit several negative effects in the treatment for T2DM, including an increased risk of bladder cancer [105], weight gain and fluid retention leading to edema. Even though pioglitazone is well tolerated in the treatment of elderly patients with renal impairment and does not cause hypoglycemia, its use should be avoided in older patients with congestive or class III-IV heart failure. Rosiglitazone and troglitazone have been withdrawn from the market considering the increased risk of myocardial infarction [106] and idiosyncratic hepatotoxicity [107], respectively.

a-Glucosidase inhibitors (AGIs): a-Glucosidase inhibitors (AGIs), including acarbose, voglibose and miglitol, are markedly effective for postprandial hyperglycemia. They inhibit intestinal mucosal enzyme (a-glucosidase) which converts complex polysaccharides into monosaccharides, thus decreasing carbohydrate absorption. Voglibose can significantly improve glucose tolerance [108] and acarbose (precose) would reduce the risk of cardiovascular diseases such as acute myocardial infarction in T2DM [109]. Side effects such as abdominal bloating, diarrhea and flatulence are always observed after the use of this class of drugs. Their use should be limited in older adults because of gastrointestinal side effects and frequent dosing should be avoided in patients with significant renal impairment [110].

Incretin-based therapies: Incretins are hormones that stimulate insulin secretion and suppress postprandial glucagon secretion in a glucose-dependent manner. They are secreted from intestinal endocrine cells, including glucose-dependent insulinotropic polypeptide (GIP) and glucagon-like peptide-1 (GLP-1). Incretin-based therapy is ideal for T2DM management because of its efficacy, good tolerability, low risk of hypoglycemia, and weight loss [111]. 
Furthermore, it may also have positive effects on inflammation, sleep, cardiovascular and hepatic health, and central nervous system.

GLP-1 receptor agonists: GLP-1 receptor agonists, including exenatide and liraglutide, can reduce hemoglobin A1c (HbA1c) levels by $0.8 \%$ to $1.5 \%$ [112]. GLP-1 receptor agonists are effective in the regulation of glucose metabolism, such as stimulating insulin production, inhibiting glucagon release, slowing nutrient absorption, and increasing feelings of satiety [94]. Because this class of agents is not specifically designed for older diabetic patients, there is no statistical difference in efficacy and safety profiles between elderly and younger patients [113]. Here, some antidiabetic agents for the treatment of T2DM are summarized in Table 2.

Table 2. Representative antidiabetic agents for the management of patients with T2DM

\begin{tabular}{|c|c|c|c|c|c|}
\hline Class & Drug (s) & Target & Action (s) & Disadvantages & Ref. \\
\hline Biguanides & Metformin & AMP-kinase & $\begin{array}{l}\text { blood glucose } \downarrow \\
\text { insulin sensitivity } \uparrow \\
\text { cardiovascular risk } \downarrow \\
\text { hypoglycemia risk } \downarrow\end{array}$ & $\begin{array}{l}\text { GI side effects } \\
\text { lactic acidosis } \\
\text { Vitamin B12 and } \\
\text { folate deficiency }\end{array}$ & {$[92,93,110,114]$} \\
\hline Sulfonylureas & $\begin{array}{l}\text { Glyburide/ } \\
\text { Glipizide/ } \\
\text { Gliclazide/ } \\
\text { Glimepiride }\end{array}$ & $\begin{array}{l}\text { ATP-sensitive, } \\
\mathrm{K}+\text { channels }\end{array}$ & insulin secretion $\uparrow$ & $\begin{array}{l}\text { hypoglycemia } \\
\text { weight gain }\end{array}$ & {$[100,101,114]$} \\
\hline TZDs & $\begin{array}{l}\text { Troglitazone/ } \\
\text { Roziglitazone/ } \\
\text { Pioglitazone }\end{array}$ & PPAR- $\gamma$ & $\begin{array}{l}\text { insulin sensitivity } \uparrow \\
\text { hypoglycemia risk } \downarrow \\
\text { glycemic control } \uparrow\end{array}$ & $\begin{array}{l}\text { bladder cancer risk } \uparrow \\
\text { weight gain } \\
\text { edema }\end{array}$ & {$[1,104,105]$} \\
\hline AGIs & $\begin{array}{l}\text { Acarbose/ } \\
\text { Miglitol/ } \\
\text { Voglibose }\end{array}$ & a-glucosidase & carbohydrate absorption $\downarrow$ & $\begin{array}{l}\text { GI side effects } \\
\text { dosing frequency }\end{array}$ & [110] \\
\hline GLP-1 receptor agonists & $\begin{array}{l}\text { Exenatide/ } \\
\text { Liraglutide }\end{array}$ & GLP-1 receptors & $\begin{array}{l}\text { insulin secretion } \uparrow \\
\text { glucagon secretion } \downarrow \\
\text { satiety } \uparrow \\
\text { hypoglycemia risk } \downarrow\end{array}$ & $\begin{array}{l}\text { GI side effects } \\
\text { acute pancreatitis } \\
\text { renal dysfunction } \\
\text { thyroid C-cell tumors in rodents }\end{array}$ & {$[110,112]$} \\
\hline
\end{tabular}

Currently, treatment guidelines generally recommend the use of metformin monotherapy as initial treatment. When T2DM patients cannot be well controlled by lifestyle and single oral antidiabetic drugs, it may be necessary to consider combination therapy with two or more antidiabetic drugs such as a thiazolidinedione plus metformin or a dipeptidyl peptidase-4 (DPP-4) inhibitor plus metformin [115, 116]. The combination therapy has several advantages over monotherapy: (1) greater efficacy with lower-dose; (2) reduced risk of negative effect; (3) lower costs; (4) improved medication concordance [117].

Insulin and insulin analogues. Insulin, the most effective anti-hyperglycemic agent, was discovered by Banting and Best in 1921. Since then, it has brought about great advances in the treatment of T2DM. Insulin therapy can provide effective glycemic control even when oral antidiabetic medicines are inadequate, and can improve many of the metabolic abnormalities in T2DM patients. The mechanism underlying the reduction of glucose concentrations by insulin is mainly through suppressing hepatic glucose production, increasing postprandial glucose utilization, and improving abnormal lipoprotein composition. Moreover, insulin therapy can improve insulin sensitivity and $\beta$-cell secretary function by the reduction of hyperglycemia, thus decreasing or eliminating the effects of glucose toxicity. In addition, it can suppress ketosis and contribute to delaying diabetic complications. Insulin has four injectable forms, including rapid acting, short acting, intermediate acting and long acting, among which the long acting forms are least likely to cause hypoglycemia.

Insulin analogues have different pharmacokinetic profiles, compared to that of regular insulin, and their onset and duration of action range from rapid to prolonged. At present, rapid-acting insulin analogues (insulin lispro and insulin aspart) and long-acting insulin analogues (insulin glargine and detemir) are available [118]. Long-acting insulin analogues can provide a prolonged duration of action and reduce the risk of hypoglycaemic events, especially nocturnal events [119].

When lifestyle changes and oral antidiabetic agents fail to achieve adequate glycemic control in T2DM patients, it is generally required for the patients to initiate insulin therapy. Numerous reviews introduced the effectiveness of combination therapy with insulin and oral antidiabetic agents in T2DM patients $[120,121]$. For example, Baruah et al. used GLP-1 analogue and insulin as a fixed dose combination (FDC) therapy in a wide range of population, and demonstrated that fasting and postprandial glucose could be effectively controlled and the therapy was well tolerated [122].

New therapeutic strategies. Although oral anti- 
diabetic agents and insulin are currently used for the treatment of T2DM and have brought about promising outcomes, problems still exist such as inadequate efficacy and adverse effects. We thus need to examine novel therapy strategies.

SGLT2 inhibitors: Sodium glucose co-transporter type 2 (SGLT2) inhibitors are a new class of glucose-lowering agents which prevent the reabsorption of renal-filtered glucose back into the circulation [123] and increase urinary glucose elimination, thus lowering blood glucose levels [124]. They have been shown to be effective in reducing $\mathrm{HbA1c}$, fasting plasma glucose (FPG), systolic blood pressure, bodyweight, as well as hyperglycaemia [125]. Dapagliflozin, one of the most advanced SGLT2 inhibitors, has been confirmed effective either as monotherapy [126] or as add-on therapy with metformin [127] and insulin [128]. Adverse effects observed in the treatment of T2DM patients with dapagliflozin include genital infections and the occurrence of breast and bladder cancer [129]. Long-term observational studies are, therefore, needed to examine possible negative effects.

DPP-4 inhibitors: Dipeptidyl peptidase-4 (DPP-4) inhibitors can improve the action of endogenous active GLP-1 and GIP by blocking its degradation by DPP-4 enzyme [130]. They are effective in the protection of pancreatic $\beta$ cells and promotion of normal glucagon secretion, thus inhibiting the progression of T2DM. DPP-4 inhibitors are well tolerated because they play pivotal roles in cardiovascular protection and anti-arteriosclerotic action, with few gastrointestinal side effects and weight neutrality [131]. So far, available DPP-4 inhibitors include vildagliptin, sitagliptin, saxagliptin and linagliptin, which have been assessed in a variety of clinical studies about their pharmacokinetics/pharmacodynamics, safety, efficacy, and tolerability [132]. Vildagliptin, one of the representative drugs, shows long-term advantages in the preservation of $\alpha-$ and $\beta$-cell functions, decrease in fasting lipolysis in adipose tissue, reduction in total cholesterol and lipotoxicity, and triglyceride storage in non-fat tissues such as muscle, pancreas and liver, with little drug interactions [133]. Sitagliptin, another leading agent, available for use in Japan for the past few years, is now used in many T2DM patients with low insulin secretory capacity [134], whose efficacy and safety have been confirmed in many clinical practices [135].

Lixisenatide: Lixisenatide (Lyxumia $\left.{ }^{\circledR}\right)$, a glucagon-like peptide (GLP)-1 receptor agonist, was approved for marketing by the European Medicines Agency in February 2013. Lixisenatide can activate the GLP-1 receptor, thus contributing to increasing insulin secretion, inhibition of glucagon secretion and de- creasing gastrointestinal motility to promote satiety [136]. In the GetGoal study program, HbA1c, FPG, and postprandial plasma glucose (PPG) were effectively decreased by the use of lixisenatide. Furthermore, lixisenatide reduced bodyweight and had therapeutic effects on glycemia when used as monotherapy or combined therapy with insulin and oral antidiabetic drugs. Nowadays, the primary combined therapy of lixisenatide seems to be with basal insulin, and clinical development as a combination product with insulin glargine (Lantus $\left.{ }^{\circledR}\right)$ is still undergoing.

GPR40 agonists: $\mathrm{G}$ protein-coupled receptor 40 (GPR40) is a free fatty acid (FFA) receptor and Gq-type, Gq-coupled G protein-coupled receptor which is highly expressed in pancreatic $\beta$-cells [137]. The stimulation of GPR40 with FFAs leads to insulin secretion through $\beta$-cell-specific signaling pathway, which can be inhibited by the treatment with small interfering RNA [138]. A large number of chemical compounds which can act as GPR40 agonists exhibit glucose-dependent insulin secretion in vitro and in vivo, among which TAK-875 can reduce fasting plasma glucose and HbA1c levels in clinical trials [139]. Recently, Tanaka and his colleagues reported three novel GPR40 agonists AS2031477, AS1975063 and AS2034178, which could improve both acute glucose-dependent insulin secretion and chronic whole-body glucose metabolism [140]. Among these GPR40 agonists, AS2034178 has been shown to reduce microvascular complications, thus it has a therapeutic potential to improve the prognosis of T2DM patients. In conclusion, GPR40 agonists represent a new class of drugs in the treatment of T2DM, especially AS2034178 is the most promising candidate.

Nitrate/Nitrite: Nitric oxide (NO) is a simple ubiquitous molecule which can play significant roles in almost every biological system. It is synthesized from L-arginine by NO synthase (NOS) enzymes including neuronal (nNOS), inducible (iNOS), endothelial (eNOS), and mitochondrial (mtNOS) NOS. In the body, nearly $90 \%$ of $\mathrm{NO}$ is converted to nitrate $\left(\mathrm{NO}_{3}{ }^{-}\right)$, a stable end-product of $\mathrm{NO}$ [141]. It has been demonstrated that $\mathrm{NO}_{3}{ }^{-}$and nitrite $\left(\mathrm{NO}_{2}{ }^{-}\right)$may have some therapeutic implications, such as decreasing blood pressure [142], reducing oxidative stress [143], and reducing oxygen consumption during exercise. It is also demonstrated that inorganic nitrate therapy can reduce visceral fat accumulation, lower serum triglycerides and normalize a disturbed glucose tolerance in eNOS deficient mice [144]. These findings suggest the roles of $\mathrm{NO}_{3}{ }^{-}$and $\mathrm{NO}_{2}{ }^{-}$in the prevention and treatment of T2DM for reduced weight in long-term $\mathrm{NO}_{3}{ }^{-}$therapy [145]. However, harmful effects exist in the $\mathrm{NO}_{3}{ }^{-} / \mathrm{NO}_{2}{ }^{-}$therapy: high levels of plasma $\mathrm{NO}_{3}^{-}$(1) increase arterial pressure; (2) may 
cause early onset of hypertension; (3) increase incidence of diabetes; (4) induce kidney dysfunction; and (5) produce hypothyroidism [146]. All in all, $\mathrm{NO}_{3}{ }^{-} / \mathrm{NO}_{2}{ }^{-}$shows potential roles in new therapeutic applications for human health, and also does potential human risks. $\mathrm{NO}_{3}-/ \mathrm{NO}_{2}-$ derived from natural sources such as vegetables may be one of the ideal choices. Further investigations are necessary in this field, especially in the identification of individuals who may benefit from the $\mathrm{NO}_{3}{ }^{-} / \mathrm{NO}_{2}{ }^{-}$therapy.

Stem cell educator therapy: Evidence has suggested that T2DM patients always display multiple immune dysfunctions and chronic metabolic inflammation. Researches have shown that monocytes/macrophages may be main players which contribute to these chronic inflammations and insulin resistance in T2DM patients [147]. Stem cell educator therapy, a novel technology, is designed to control or reverse immune dysfunctions [148]. The procedure includes: collection of patients' blood circulating through a closed-loop system, purification of lymphocytes from the whole blood, co-culture of them with adherent cord blood-derived multi-potent stem cells (CB-SCs) in vitro and administration of the educated lymphocytes (but not the CB-SCs) to the patient's circulation [149] (Fig. 3). Current phase I/ phase II studies suggest the safety and therapeutic efficacy of this kind of therapy in T2DM, with remarkably increased insulin sensitivities and notable improvement of metabolic control in T2DM patients [150]. This new method exhibits great benefits in improving treatment and cure for T2DM, particularly in early-stage diabetic patients, which may help to cope with diabetes-associated complications and improve the quality of their life.

Anti-inflammatory treatment: It has been demonstrated that apparent changes in the immune system occur in T2DM, especially in adipose tissue, pancreatic islets, the liver, the vasculature and circulating leukocytes [151], which include altered levels of specific cytokines and chemokines, the number and activation state of different leukocyte populations, increased apoptosis and tissue fibrosis. These changes indicate that inflammation plays a pivotal role in the pathogenesis of T2DM and its complications. Salicylates and interleukin-1 antagonists are the representative drugs with immunomodulatory effects in the treatment of T2DM patients, which can lower blood glucose levels and reduce severity and prevalence of the associated complications [152, 153]. Recently, phase III clinical trials are ongoing [154].

Antioxidant therapy: Antioxidant therapy may be another new effective way for the treatment of T2DM patients [155], which may play important roles in lowering the risk of developing diabetes and its complications. A variety of antioxidants, such as vitamins, supplements, plant-derived active substances and drugs with antioxidant effects, have been used for oxidative stress treatment in T2DM patients. Vitamin $C$, vitamin $E$ and $\beta$ carotene are ideal supplements against oxidative stress and its complications [76]. For example, vitamin $\mathrm{C}$ can decrease fasting plasma insulin and $\mathrm{HbA1c}$ level, improve insulin action, and $\beta$ carotene may reduce oxidative LDL [156]. Plants which contain substances with antioxidant properties such as monoterpenes, cinnamic acids, coumarins, flavonoid, diterpenes, phenylpropanoids, triterpenes, tannins and lignin can provide therapeutic effects in the treatment of T2DM [76]. Drugs with antioxidant properties, for example, a-lipoic acid and carvedilol, also have antioxidant effects in T2DM [156].
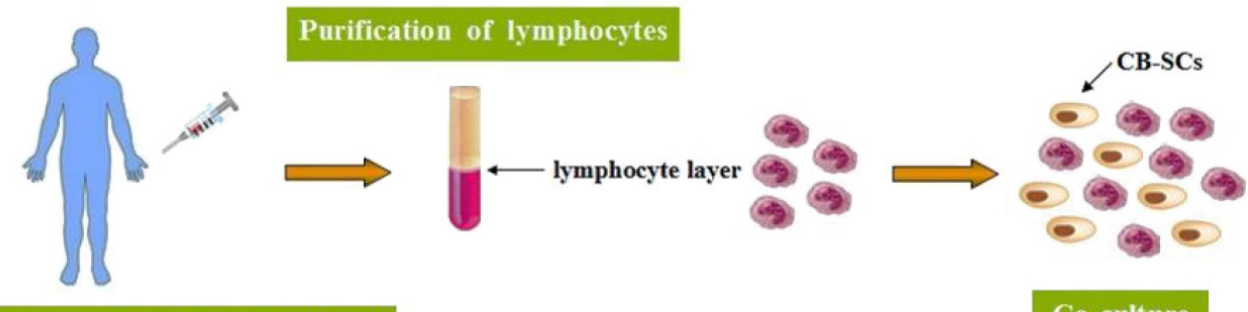

Collection of patients' blood

Co-culture
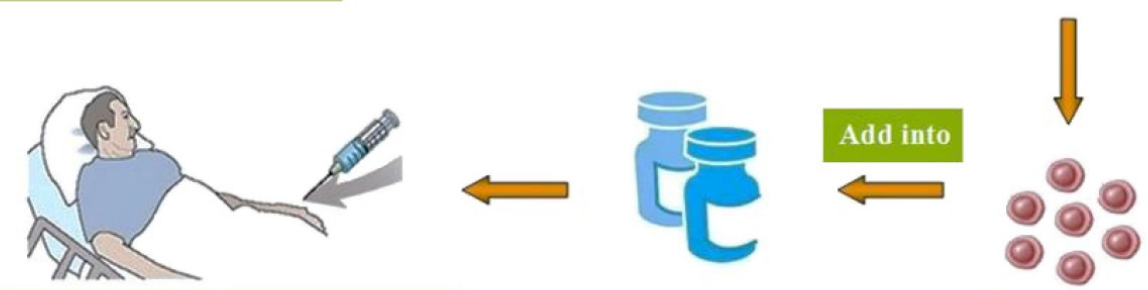

Administration in patient's circulation

physiological saline

educated mononuclear cells

Figure 3. The procedure of stem cell educator therapy. 


\section{Risk assessment}

Statistically, about $50 \%$ of people with diabetes remain undiagnosed and approximately $20-30 \%$ patients usually have already developed complications before being diagnosed [157]. An alternative screening approach is thus urgently required for the earlier diagnose of T2DM. At present, a variety of risk assessment tools based on self-assessed, biochemical measures or genetic markers have been developed for the prediction of T2DM, which are more practical and valuable than conventional blood glucose screening test, so that interventions can be applied to those with impaired glucose tolerance to delay the onset of T2DM.

Prediction models with noninvasive measures. Noninvasive measures require information about age, sex, height, waist circumference, BMI, ethnicity, history of hypertension and prevalent/latent diabetes, medication use, physical activity, and consumption of berries alcohol, coffee, whole grains, fruits, vegetables, red meat and so on [158, 159]. FINDRISC (Finnish Diabetes Risk Score) questionnaire, the most commonly used method [160], is designed to self-assess the risk on the basis of seven questions, which has a good validity in the prediction of future diabetes onset over a 10-year period [158]. The other approach is based on the data which are routinely available to the general practitioner, for example, the CRS or the QDScore ${ }^{\circledR}$ (ClinRisk, Leeds, UK) [161-163]. Researches have demonstrated that noninvasive screening tools are more cost-effective than a blood test as a first stage screening, and risk scores show good sensitivity and specificity for the identification of prevalence or incident of impaired glucose regulation or T2DM [164].

Prediction models including biochemical measure. Biochemical testing plays an essential role in the identification of individuals with high risk for developing T2DM $[165,166]$. It usually involves a multi-step procedure: firstly, simple questionnaires or noninvasive measures; then, measurement of biochemical makers in prescreened individuals.

Many studies have been conducted to evaluate the prediction models for metabolic syndromes in terms of sensitivities, specificities, and predicted values along with basic noninvasive information. Generally, they include concentrations of blood lipids (e.g. high density lipoprotein cholesterol, triglycerides), plasma glucose (either fasting or 2-hour), blood pressure and waist circumference [167-169]. Among them, triglyceride and high density lipoprotein cholesterol can be easily obtained in clinical practice and can slightly increase the predictive value. In particular, fasting plasma glucose can obviously improve the predictive value based on noninvasive measures.

Some novel biochemical markers include C-reactive protein, liver enzymes and so on. In the European Prospective Investigation into Cancer and Nutrition-Potsdam (EPIC-Potsdam) Study, C-reactive protein has not shown added prognostic information beyond the extended prediction model, whereas liver enzymes with concentrations of blood lipids can obviously improve prediction beyond the noninvasive parameters and measures of glycemia [170]. Besides, a risk score from Taiwan shows that white blood cell count can also improve prediction, although the accuracy of the derived score is low [171].

Prediction models involving genetic maker. A large number of genetic variants have been investigated for the prediction value of T2DM [172, 173], and they marginally improved prediction beyond noninvasive characteristics in those studies. Because the accuracy of prediction relies on many factors such as the number of genes involved, the frequency of the risk alleles, and the risks correlated with the genotypes [174, 175], many additional common variants with small effect sizes or rare variants with stronger effect sizes must be further identified. It is always a time-consuming and painstaking project to identify novel diabetes genes by GWAS, which requires many cases for sufficient statistical power to ensure a very modest increase in risk of each risk allele. Even though these have been done successfully, it still needs to consider how the information can be provided to patients and whether it will encourage people to adopt healthy lifestyles and medical interventions.

\section{Lifestyle intervention for prevention of T2DM}

Physical activity interventions. Nowadays, physical inactivity has been considered as one of the biggest public health problems worldwide [176]. It is demonstrated that physical activity may contribute to $30-50 \%$ reduction in the development of T2DM [177]. Physical activity interventions can improve glucose tolerance and reduce the risk of T2DM [178], because it simply help achieve weight loss [179]. Any types of physical activity should be acceptable to the majority of the population. For example, walking, the most popular choice of physical activity, has been shown to reduce the relative risk of T2DM by $60 \%$ when walk for $150 \mathrm{~min} /$ week, compared to walking for $<60$ min/week [180]. It is widely advocated to keep a daily step, which is an effective self-regulatory strategy to successfully promote increased physical activity. For people who have difficulty in walking because of joint problems, other forms of physical activity, for example, cycling, swimming or gym-based activities, 
should be encouraged.

Healthy eating. Diabetes prevention studies have demonstrated that diet composition is another important factor to prevent the development of T2DM. Epidemiological studies have suggested that the risk of diabetes can be increased or decreased owing to dietary factors. The dietary factors which may increase the diabetes risk are consuming excessive amounts of refined grains, sugar-sweetened beverages, red and processed meat and alcohol, and those with the opposite effects are the intake of whole-grain cereal, vegetables, dairy, legumes, nuts, independently of body weight change [181-183].

A large number of prevention studies concerning dietary factors have been conducted in many countries during the past several years. Studies from China, Japan and India aimed at examining the effects of reducing fat, refined carbohydrates and alcohol and increasing fibre intake on the development of T2DM [184-186]. The Finnish Diabetes Prevention Study (DPS) advocated decreasing total and saturated fat intake and increasing fibre density in the diet [187]. In the Diabetes Prevention Program (DPP), dietary goals were to reduce total fat and energy intake [188]. A Mediterranean diet characterized by a high intake of vegetables, fruit, legumes, extra virgin olive oil, nuts, fish, whole grains and red wine also showed a remarkable decrease in the incidence of diabetes in a Spanish study [189].

Even though diet is quite variable owing to food availability, personal preferences and different cultures, a general rule can be derived: a high intake of vegetables, fruits and fat from vegetables with low saturated fat content should be preferred; nuts, legumes, dairy and fish should be taken as supplement for enough body protein; grain products unrefined and with high natural fiber content should be mainly chosen; red meat and highly processed foods should be limited (e. g., processed meat, confectionery).

Behavior change interventions. It has been shown that behavior change interventions can prevent or delay the development of T2DM for people with high risk [190]. For instance, the DPS and DPP demonstrated that changes in diet or physical activity could reduce the diabetes incidence by almost $60 \%$ in 4 years [98, 191]. Vermunt group took behavior change techniques including motivational interviewing, filling out decisional balance sheets, goal setting, developing action plans, barrier identification, relapse prevention [192]. However, barriers existed for the achievement of lifestyle change, one of which is continuity. For the weight loss and dietary improvement, it is considerably difficult to resist temptation to snacks, which needs to seek good techniques to control internal and external stimuli [193]. Examples for the stimulus control are encouraging people to avoid cues for snacks storage [193] and to engage in social support [194, 195]. We can also identify future high-risk situations through monitoring psychological causes and habitual behavior.

Obesity management. Obesity is one of the most important risk factors for T2DM, whose basic cause is an imbalance between energy intake and expenditure [196]. Adipose tissue, particularly of the tissue surrounding internal organs (e.g. visceral fat) can secrete various proinflammatory adipokines [197], and the secretion of these cytokines will be changed if the adipose tissue mass increase, this will contribute to T2DM because of metabolic disturbances [198]. WHO has identified several lifestyle-improving factors to avoid obesity risk, including increased intake of high dietary fiber, reduced intake of energy-dense, micronutrient-poor foods and regular physical activity. Weight reduction may have effects on diabetes incidence, as seen in the DPP study, each kilogram of weight loss is correlated with a $16 \%$ reduction in the development of T2DM [199]. Weight reduction thus seems to be beneficial in the prevention of T2DM, at least in the short term [200]. Foods with low energy density, such as vegetables and fruits, are advised to increase satiety so that they can reduce total energy intake and achieve weight reduction [201]. A meta-analysis suggests that a habitual energy imbalance of about 50-100 kcal per day may contribute to the gradual weight gain [202], however, modest and sustained changes in lifestyle could lighten or reverse this status [202]. It is, therefore, more acceptable for people to change gradually in diet or activity rather than dramatically. These strategies require further investigations for the establishment of efficient prevention and control of T2DM.

\section{Conclusions}

T2DM and its related complications impose heavy health burdens worldwide and there have been not effective measures to fully cope with the diseases. The main cause of the diabetes epidemic is the interaction between genetic and environmental risk. A number of other factors are also attributable to the diseases. Whereas most antidiabetic agents have shown beneficial effects when used as monotherapy or combination therapy, they are also associated with negative effects, such as weight gain, hypoglycemia, gastrointestinal effects or cardiovascular disease. With increasing incidence of T2DM, searching an ideal therapy becomes one of the top priorities in combating this disease. To date, several therapeutic strategies have been developed, such as the use of SGLT2 inhibitors, DPP-4 inhibitors and GPR40 agonists. Above all, stem cell educator therapy opened avenues to 
develop new therapeutic strategies in the treatment of T2DM, with safety and high therapeutic efficacy. Further investigations should focus on (1) the exact mechanism contributing to T2DM and its related complications; (2) effective intervention trials and prevention measures to avoid the occurrence of this disease; (3) earlier diagnosis for earlier treatment; (4) novel drugs with more beneficial effects and less adverse effects, so as to conquer this disease and improve the quality of life and overall life span.

\section{Acknowledgments}

We gratefully acknowledge the support by the Program for Zhejiang Leading Team of Science and Technology Innovation (2011R50021) and Social Development Project of Zhejiang Province (2011C23004) and Zhejiang Provincial Natural Science Foundation of China (LY12B02019).

\section{Competing Interests}

The authors have declared that no competing interest exists.

\section{References}

1. Tripathi BK, Srivastava AK. Diabetes mellitus: complications and therapeutics. Med Sci Monit. 2006; 12(7): RA130-147.

2. Chen L, Magliano DJ, Zimmet PZ. The worldwide epidemiology of type 2 diabetes mellitus-present and future perspectives. Nat Rev Endocrinol. 2011; 8(4): 228-236.

3. Zhang $\mathrm{PH}, \mathrm{Chen} \mathrm{ZW}, \mathrm{Lv} \mathrm{D}$, et al. Increased risk of cancer in patients with type 2 diabetes mellitus: a retrospective cohort study in China. BMC Public Health. 2012; 12: 567.

4. Gastaldelli A. Role of beta-cell dysfunction, ectopic fat accumulation and insulin resistance in the pathogenesis of type 2 diabetes mellitus. Diabetes Res Clin Pract. 2011; 93(1): S60-65.

5. Ismail-Beigi F. Pathogenesis and glycemic management of type 2 diabetes mellitus: a physiological approach. Arch Iran Med. 2012; 15(4): 239-246.

6. Zhao Y, Jiang Z, Guo C. New hope for type 2 diabetics: Targeting insulin resistance through the immune modulation of stem cells. Autoimmun Rev. 2011; 11: 137-142.

7. Wild S, Roglic G, Green A, et al. Global prevalence of diabetes: estimate for the year 2000 and projections for 2030. Diabetes Care. 2004; 127(5): 1047-1053.

8. Diamond J. Medicine: diabetes in India. Nature. 2011; 469: 478-479.

9. Yang W, Lu J, Weng J, et al. Prevalence of diabetes among men and women in China. N Engl J Med. 2010; 362: 1090-1101.

10. Weigensberg MJ, Goran MI. Type 2 diabetes in children and adolescents. Lancet. 2009; 373: 1743-1744.

11. Poulsen P, Grunnet LG, Pilgaard K, et al. Increased risk of type 2 diabetes in elderly twins. Diabetes. 2009; 58(6): 1350-1355.

12. Sanghera DK, Blackett PR. Type 2 diabetes genetics: beyond GWAS. J Diabetes Metab. 2012; 3(198): pii6948.

13. Poulsen P, Kyvik KO, Vaag A, et al. Heritability of type II (non-insulin- dependent) diabetes mellitus and abnormal glucose tolerance: a population-based twin study. Diabetologia. 1999; 42: 139-145

14. Kobberling, JTH. Emperical risk figures of first degree relatives of non-insulin dependent diabetes. London: Academic Press; 1982.

15. Sladek R, Rocheleau G, Rung J, et al. A genome-wide association study identifies novel risk loci for type 2 diabetes. Nature. 2007; 445(7130): 881-885.

16. Frayling TM, Timpson NJ, Weedon MN, et al. A common variant in the FTO gene is associated with body mass index and predisposes to childhood and adult obesity. Science. 2007; 316(5826): 889-894.

17. Scott LJ, Mohlke KL, Bonnycastle LL, et al. A genome-wide association study of type 2 diabetes in Finns detects multiple susceptibility variants. Science. 2007; 316(5829): 1341-1345.

18. Saxena $\mathrm{R}$, et al. Genome-wide association analysis identifies loci for type 2 diabetes and triglyceride levels. Science. 2007; 316(5829): 1331-1336.

19. Zeggini E, Weedon MN, Lindgren CM, et al. Replication of genome-wide association signals in UK samples reveals risk loci for type 2 diabetes. Science, 2007; 316(5829): 1336-1341.

20. Steinthorsdottir V, Thorleifsson G, Reynisdottir I, et al. A variant in CDKAL1 influences insulin response and risk of type 2 diabetes. Nat Genet. 2007; 39(6): $770-775$.
21. Wellcome Trust Case Control Consortium. Genome-wide association study of 14,000 cases of seven common diseases and 3,000 shared controls. Nature. 2007; 447(7145): 661-678.

22. van Exel E, Gussekloo J, de Craen AJ, et al. Low production capacity of interleukin-10 associates with the metabolic syndrome and type 2 diabetes: the Leiden 85-Plus Study. Diabetes. 2002; 51(4): 1088-1092.

23. Hua Y, Shen J, Song Y, et al. Interleukin-10-592C/A, -819C/T and -1082A/G polymorphisms with risk of type 2 diabetes mellitus: A HuGE review and meta-analysis. PLoS One. 2013; 8(6): e66568.

24. Unoki H, Takahashi A, Kawaguchi T, et al. SNPs in KCNQ1 are associated with susceptibility to type 2 diabetes in East Asian and European populations. Nat Genet. 2008; 40(9): 1098-1102.

25. Tsai FJ, Yang CF, Chen CC, et al. A genome-wide association study identifies susceptibility variants for type 2 diabetes in Han Chinese. PLoS Genet. 2010; 6(2): e1000847.

26. Voight BF, Scott LJ, Steinthorsdottir V, et al. Twelve type 2 diabetes susceptibility loci identified through large-scale association analysis. Nat Genet. 2010; 42(7): 579-589.

27. Yasuda K, Miyake K, Horikawa Y, et al. Variants in KCNQ1 is associated with susceptibility to type 2 diabetes mellitus. Nat Genet. 2008; 40(9): 1092-1097.

28. Takeuchi F, Serizawa M, Yamamoto $\mathrm{K}$, et al. Confirmation of multiple risk Loci and genetic impacts by a genome-wide association study of type 2 diabetes in the Japanese population. Diabetes. 2009; 58(7): 1690-1699.

29. Ntzani EE, Kavvoura FK. Genetic risk factors for type 2 diabetes: insights from the emerging genomic evidence. Curr Vasc Pharmacol. 2012; 10(2): 147-155.

30. Zeggini E, Scott LJ, Saxena R, et al. Meta-analysis of genome-wide association data and large-scale replication identifies additional susceptibility loci for type 2 diabetes. Nat Genet. 2008; 40(5): 638-645.

31. Olokoba AB, Obateru OA, Olokoba LB. Type 2 diabetes mellitus: a review of current trends. Oman Med J. 2012; 27(4): 269-273.

32. Rung J, Cauchi S, Albrechtsen A, et al. Genetic variant near IRS1 is associated with type 2 diabetes, insulin resistance and hyperinsulinemia. Nat Genet. 2009; 41(10): 1110-1115.

33. Lyssenko V, Nagorny CL, Erdos MR, et al. Common variant in MTNR1B associated with increased with risk of type 2 diabetes and impaired early insulin secretion. Nat Genet. 2009; 41(1): 82-88.

34. Sanghera DK, Ortega L, Han S, et al. Impact of nine common type 2 diabetes risk polymorphisms in Asian Indian Sikhs: PPARG2 (Pro12Ala), IGF2BP2, TCF7L2 and FTO variants confer a significant risk. BMC Med Genet. 2008; 9: 59.

35. Frayling TM, Timpson NJ, Weedon MN, et al. A common variant in the FTO gene is associated with body mass index and predisposes to childhood and adult obesity. Science. 2007; 316(5826): 889-894.

36. Pearson ER, Flechtner I, Njolstad PR, et al. Switching from insulin to oral sulfonylureas in patients with diabetes due to Kir6.2 mutations. New Engl J Med. 2006; 355(5): 467-477.

37. Lehmann JM, Moore LB, Smith-Oliver TA, et al. An antidiabetic thiazolidinedione is a high affinity ligand for peroxisome proliferator-activated receptor gamma (PPAR gamma). J Biol Chem. 1995; 270(22): 12953-12956.

38. Zimmet P, Alberti KG, Shaw J. Global and societal implications of the diabetes epidemic. Nature. 2001; 414(6865): 782-787.

39. Hu FB, Manson JE, Stampfer MJ, et al. lifestyle, and the risk of type 2 diabetes mellitus in women. N Engl J Med. 2001; 345(11): 790-797.

40. Manson JE, Ajani UA, Liu S, et al. A prospective study of cigarette smoking and the incidence of diabetes mellitus among US male physicians. Am J Med. 2000; 109: 538-542

41. Cullmann M, Hilding A, Östenson CG. Alcohol consumption and risk of pre-diabetes and type 2 diabetes development in a Swedish population. Diabet Med. 2012; 29(4): 441-452.

42. Belkina AC, Denis GV. Obesity genes and insulin resistance. Curr Opin Endocrinol Diabetes Obes. 2010; 17(5): 472-477.

43. Walley AJ, Blakemore AI, Froguel P. Genetics of obesity and the prediction of risk for health. Hum Mol Genet. 2006; 15 (Spec No 2): R124-R130.

44. Pamidi S, Tasali E. Obstructive sleep apnea and type 2 diabetes: is there a link? Front Neurol. 2012; 3: 126

45. Ioja S, Weir ID, Rennert NJ. Relationship between sleep disorders and the risk for developing type 2 diabetes mellitus. Postgrad Med. 2012; 124(4): 119-129.

46. Lindberg E, Theorell-Haglöw J, Svensson M, et al. Sleep apnea and glucose metabolism: a long-term follow-up in a community-based sample. Chest. 2012; 142(4): 935-942.

47. Einhorn D, Stewart DA, Erman MK, et al. Prevalence of sleep apnea in a population of adults with type 2 diabetes mellitus. Endocr Pract. 2007; 13(4): 355-362.

48. Schober AK, Neurath MF, Harsch IA. Prevalence of sleep apnoea in diabetic patients. Clin Respir J. 2011; 5(3): 165-172.

49. Liu S, Manson JE, Stampfer MJ, Hu FB, et al. A prospective study of whole-grain intake and risk of type 2 diabetes mellitus in US women. Am J Public Health. 2000; 90(9): 1409-1415.

50. Hu FB, van Dam RM, Liu S. Diet and risk of type II diabetes: the role of types of fat and carbohydrate. Diabetologia. 2001; 44: 805-817.

51. van Dam RM, Willett WC, Rimm EB, et al. Dietary fat and meat intake in relation to risk of 2 diabetes in men. Diabetes care. 2002; 25(3): 417-424.

52. Schulze MB, Manson JE, Ludwig DS, et al. Sugar-sweetened beverages, weight gain, and incidence of type II diabetes in young and middle-aged women. JAMA. 2004; 292: 927-934. 
53. Dhingra $\mathrm{R}$, Sullivan $\mathrm{L}$, Jacques $\mathrm{PF}$, et al. Soft drink consumption and risk of developing cardio-metabolic risk factors and the metabolic syndrome in middle-aged adults in the community. Circulation. 2007; 116: 480-488.

54. Duffey KJ, Popkin BM. Adults with healthier dietary patterns have healthier beverage patterns. J Nutr. 2006; 136: 2901-2907.

55. Musso G, Gambino R, Cassader M. Interactions between gut microbiota and host metabolism predisposing to obesity and diabetes. Annu Rev Med. 2011; 62: 361-380.

56. Woo PC, Lau SK, Woo GK, et al. Bacteremia due to Clostridium hathewayi in a patient with acute appendicitis. J Clin Microbiol. 2004; 42(12): 5947-5949.

57. Elsayed S, Zhang K. Bacteremia caused by Clostridium symbiosum. J Clin Microbiol. 2004; 42(9): 4390-4392.

58. Qin J, Li Y, Cai Z, et al. A metagenome-wide association study of gut microbiota in type 2 diabetes. Nature. 2012; 490(7418): 55-60.

59. Lyssenko V, Jonsson A, Almgren P, et al. Clinical risk factors, DNA variants, and the development of type 2 diabetes. N Engl J Med. 2008; 359(21): 2220-2232.

60. Mitri J, Dawson-Hughes B, Hu FB, et al. Effects of vitamin D and calcium supplementation on pancreatic $\beta$ cell function, insulin sensitivity, and glycemia in adults at high risk of diabetes: the calcium and vitamin D for diabetes mellitus (CaDDM) randomized controlled trial. Am J Clin Nutr. 2011; 94(2): 486-494.

61. Nikooyeh B, Neyestani TR, Farvid M, et al. Daily consumption of vitamin Dor vitamin D + calcium- fortified yogurt drink improved glycemic control in patients with type 2 diabetes: a randomized clinical trial. Am J Clin Nutr. 2011; 93(4): 764-771.

62. Pittas AG, Sun Q, Manson JE, et al. Plasma 25-hydroxyvitamin D concentration and risk of incident type 2 diabetes in women. Diabetes Care. 2010; 33(9): 2021-2023.

63. Thorand B, Zierer A, Huth C, et al. Effect of serum 25-hydroxyvitamin D on risk for type 2 diabetes may be partially mediated by subclinical inflammation: results from the MONICA/KORA Augsburg study. Diabetes Care. 2011; 34(10): 2320-2322.

64. Chagas CE, Borges MC, Martini LA, et al. Focus on vitamin D, inflammation and type 2 diabetes. Nutrients. 2012; 4(1):52-67.

65. Pittas AG, Dawson-Hughes B. Vitamin D and diabetes. J Steroid Biochem Mol Biol. 2010; 121(1-2): 425-429.

66. Wolden-Kirk H, Overbergh L, Christesen HT, et al. Vitamin D and diabetes: its importance for beta cell and immune function. Mol Cell Endocrinol. 2011; 347(1-2): 106-120.

67. Takiishi T, Gysemans C, Bouillon R, et al. Vitamin D and diabetes. Endocrinol Metab Clin North Am. 2010; 39(2): 419-446.

68. Iwamoto J, Takeda T, Sato Y. Effects of vitamin K2 on osteoporosis. Curr Pharm Des. 2004; 10: 2557-2576.

69. Tabb MM, Sun A, Zhou C, et al. Vitamin K2 regulation of bone homeostasis is mediated by the steroid and xenobiotic receptor SXR. J Biol Chem. 2003; 278(45): 43919-43927.

70. Yoshida M, Booth SL, Meigs JB, et al. Phylloquinone intake, insulin sensitivity, and glycemic status in men and women. Am J Clin Nutr. 2008; 88: 210-215.

71. Iwamoto J, Takeda T, Sato Y. Menatetrenone (vitamin K 2) and bone quality in the treatment of postmenopausal osteoporosis. Nutr Rev. 2006; 64: 509-517.

72. Kobayashi M, Hara K, Akiyama Y. Effects of vitamin K2 (menatetrenone) and alendronate on bone mineral density and bone strength in rats fed a low-magnesium diet. Bone. 2004; 35: 1136-1143.

73. Iwamoto J, Matsumoto $\mathrm{H}$, Takeda $\mathrm{T}$, et al. Effects of vitamin $\mathrm{K} 2$ and risedronate on bone formation and resorption, osteocyte lacunar system, and porosity in the cor-tical bone of glucocorticoid-treated rats. Calcif Tissue Int. 2008; 83: 121-128.

74. Iwamoto J, Matsumoto $\mathrm{H}$, Takeda $\mathrm{T}$, et al. Effects of vitamin $\mathrm{K} 2$ on cortical and cancellous bone mass, cortical osteocyte and lacunar system, and porosity in sciatic neurectomized rats. Calcif Tissue Int. 2010; 87: 254-262.

75. Iwamoto J, Seki A, Sato Y, et al. Vitamin K2 promotes bone healing in a rat femoral osteotomy model with or without glucocorticoid treatment. Calcif Tissue Int. 2010; 86(3): 234-241.

76. Chaturvedi N. The burden of diabetes and its complications: Trends and implications for intervention. Diabetes Res Clin Pract. 2007; 76(3): S3-S12.

77. Vigersky RA. An overview of management issues in adult patients with type 2 diabetes mellitus. J Diabetes Sci Technol. 2011; 5(2): 245-250.

78. Zatalia SR, Sanusi H. The role of antioxidants in the pathophysiology, complications, and management of diabetes mellitus. Acta Med Indones. 2013; 45(2): 141-147.

79. Fong DS, Aiello L, Gardner TW, et al. Retinopathy in diabetes. Diabetes Care. 2004; 27(1): S84-87.

80. Elwing JE, Gao F, Davidson NO, et al. Type 2 diabetes mellitus: the impact on colorectal adenoma risk in women. Am J Gastroenterol. 2006; 101(8): 1866-1871.

81. Donadon V, Balbi M, Casarin P, et al. Association between hepatocellular carcinoma and type 2 diabetes mellitus in Italy: potential role of insulin. World J Gastroenterol. 2008; 14(37): 5695-5700.

82. Larsson SC, Andersson SO, Johansson JE, et al. Diabetes mellitus, body size and bladder cancer risk in a prospective study of Swedish men. Eur J Cancer. 2008; 44: 2655-2660.

83. Larsson SC, Mantzoros CS, Wolk A. Diabetes mellitus and risk of breast cancer: a meta-analysis. Int J Cancer. 2007; 121: 856-862.
84. Larsson SC, Wolk A. Diabetes mellitus and incidence of kidney cancer: a meta-analysis of cohort studies. Diabetologia. 2011; 54: 1013-1018.

85. Giovannucci E, Harlan DM, Archer MC, et al. Diabetes and cancer: a consensus report. CA Cancer J Clin. 2010; 60(4): 207-221.

86. Schoen RE, Weissfeld JL, Kuller LH, et al. Insulin-like growth factor-I and insulin are associated with the presence and advancement of adenomatous polyps. Gastroenterology. 2005; 129: 464-475.

87. Tran TT, Naigamwalla D, Oprescu AI, et al. Hyperinsulinemia, but not other factors associated with insulin resistance, acutely enhances colorectal epithelial proliferationin vivo. Endocrinology. 2006; 147: 1830-1837.

88. Sandhu MS, Dunger DB, Giovannucci EL. Insulin, insulin-like growth factor-I (IGF-I), IGF binding proteins, their biologic interactions, and colorectal cancer. J Natl Cancer Inst. 2002; 94(13): 972-980.

89. Wu X, Zhao H, Do KA, et al. Serum levels of insulin growth factor (IGF-I) and IGF-binding protein predict risk of second primary tumors in patients with head and neck cancer. Clin Cancer Res. 2004; 10: 3988-3995

90. Yu H, Spitz MR, Mistry J, et al. Plasma levels of insulin-like growth factor-I and lung cancer risk: a case-control analysis. J Natl Cancer Inst. 1999; 91(2): 151-156.

91. Holman R. Metformin as first choice in oral diabetes treatment: the UKPDS experience. Journ Annu Diabetol Hotel Dieu. 2007::13-20.

92. Hundal RS, Inzucchi SE. Metformin: new understandings, new uses. Drugs. 2003; 63(18): 1879-1894.

93. Collier CA, Bruce CR, Smith AC, et al. Metformin counters the insulin-induced suppression of fatty acid oxidation and stimulation of triacylglycerol storage in rodent skeletal muscle. Am J Physiol Endocrinol Metab. 2006; 291(1): E182-189.

94. Rodbard HW, Blonde L, Braithwaite SS, et al. American Association of Clinical Endocrinologists medical guidelines for clinical practice for the management of diabetes mellitus. Endocr Pract. 2007; 13 (Suppl 1): S1-S68.

95. Erlich DR, Slawson DC, Shaughnessy A. Diabetes update: new drugs to manage type 2 diabetes. FP Essent. 2013; 408: 20-24.

96. Bailey CJ, Turner RC. Metformin. N Engl J Med. 1996; 334(9): 574-579.

97. Kim YD, Park KG, Lee YS, et al. Metformin inhibits hepatic gluconeogenesis through AMP-activated protein kinase-dependent regulation of the orphan nuclear receptor SHP. Diabetes. 2008; 57(2): 306-314.

98. Knowler WC, Barrett-Connor E, Fowler SE, et al. Reduction in the incidence of type 2 diabetes with lifestyle intervention or metformin. N Engl J Med. 2002; 346(6): 393-403.

99. Ripsin CM, Kang H, Urban RJ. Management of blood glucose in type 2 diabetes mellitus. Am Fam Physician. 2009; 79(1): 29-36.

100. Ashcroft FM, Rorsman P. KATP channels and islet hormone secretion: new insights and controversies. Nat Rev Endocrinol. 2013; 9(11): 660-669.

101. Phung OJ, Schwartzman E, Allen RW, et al. Sulphonylureas and risk of cardiovascular disease: systematic review and meta-analysis. Diabet Med. 2013; 30(10): 1160-1171.

102. Scheen AJ. Drug interactions of clinical importance with antihyperglycaemic agents: an update. Drug Saf. 2005; 28(7): 601-631.

103. Uwaifo GI, Ratner RE. Differential effects of oral hypoglycemic agents on glucose control and cardiovascular risk. Am J Cardiol. 2007; 99(4A): 51B-67B.

104. Hevener AL, Olefsky JM, Reichart D, et al. Macrophage PPAR gamma is required for normal skeletal muscle and hepatic insulin sensitivity and fullantidiabetic effects of thiazolidinediones. J Clin Invest. 2007; 117(6): 1658-1669.

105. Mamtani R, Haynes $\mathrm{K}$, Bilker WB, et al. Association between longer therapy with thiazolidinediones and risk of bladder cancer: a cohort study. J Natl Cancer Inst. 2012; 104: 1411-1421.

106. Yoon $\mathrm{KH}$, Lee JH, Kim JW, et al. Epidemic obesity and type 2 diabetes in Asia. Lancet. 2006; 368(9548): 1681-1688.

107. Saleh YM, Mudaliar SR, Henry RR: Metabolic and vascular effect of the thiazolidinedione Troglitazone. Diabetes Rev. 2000; 7: 55-76.

108. Kawamori R, Tajima N, Iwamoto Y, et al. Voglibose for prevention of type 2 diabetes mellitus: a randomised, double-blind trial in Japanese individuals with impaired glucose tolerance. Lancet. 2009; 373(9675): 1607-1614.

109. Chiasson JL, Josse RG, Gomis R, et al. Acarbose treatment and the risk of cardiovascular disease and hypertension in patients with impaired glucose tolerance. JAMA. 2003; 290(4): 486-494.

110. Kim KS, Kim SK, Sung KM, et al. Management of type 2 diabetes mellitus in older adults. Diabetes Metab J. 2012; 36(5): 336-344.

111. Calabrese D. Differentiating incretin-based therapies for population-based health care. Am J Manag Care. 2011; 17 (Suppl 2): S52-S58.

112. Kurukulasuriya LR, Sowers JR. Therapies for type 2 diabetes: lowering HbA1c and associated cardiovascular risk factors. Cardiovasc Diabetol. 2010; 9: 45.

113. Bourdel-Marchasson I, Schweizer A, Dejager S. Incretin therapies in the management of elderly patients with type 2 diabetes mellitus. Hosp Pract (Minneap). 2011; 39: 7-21.

114. American Diabetes Association. Standards of medical care in diabetes-2012. Diabetes Care. 2012; 35 (Suppl 1):S11-S63.

115. Ahren B. Are sulfonylureas less desirable than DPP-4 inhibitors as add-on to metformin in the treatment of type 2 diabetes? Curr Diab Rep. 2011; 11: 83-90.

116. Scheen AJ. Linagliptin plus metformin: a pharmacokinetic and pharmacodynamic evaluation. Expert Opin Drug Metab Toxicol. 2013; 9(3): 363-377.

117. Bell DS. Combine and conquer: advantages and disadvantages of fixed-dose combination therapy. Diabetes Obes Metab. 2013; 15(4): 291-300. 
118. Belhadj M, Dahaoui A, Jamoussi H, et al. Exploring insulin analogue safety and effectiveness in a Maghrebian cohort with type 2 diabetes: results from the $\mathrm{A}_{1}$ chieve study. Diabetes Res Clin Pract. 2013; 101 (Suppl 1): S4-S14.

119. Bullano MF, Al-Zakwani IS, Fisher MD, et al. Differences in hypoglycemia event rates and associated cost-consequence in patients initiated on long-acting and intermediate-acting insulin products. Curr Med Res Opin. 2005; 21(2): 291-298.

120. Sinclair AJ, Paolisso G, Castro M, et al. European Diabetes Working Party for Older People 2011 clinical guidelines for type 2 diabetes mellitus. Executive summary. Diabetes Metab. 2011; 37 (Suppl 3): S27-S38.

121. Kuritzky L. Addition of basal insulin to oral antidiabetic agents: a goal-directed approach to type 2 diabetes therapy. MedGenMed. 2006; 8(4): 34 .

122. Baruah MP, Kalra S. The novel use of GLP-1 analogue and insulin combination in type 2 diabetes mellitus. Recent Pat Endocr Metab Immune Drug Discov. 2012; 6(2): 129-135.

123. Hanefeld M, Forst T. Dapagliflozin, an SGLT2 inhibitor, for diabetes. Lancet. 2010; 375(9733): 2196-2198

124. Bays H. Sodium Glucose Co-transporter Type 2 (SGLT2) Inhibitors: targeting the kidney to improve glycemic control in diabetes mellitus. Diabetes Ther. 2013; 4(2): 195-220.

125. Clar C, Gill JA, Court R, et al. Systematic review of SGLT2 receptor inhibitors in dual or triple therapy in type 2 diabetes. BMJ Open. 2012; 2(5): e001007.

126. Ferrannini E, Ramos SJ, Salsali A, et al. Dapagliflozin monotherapy in type 2 diabetic patients with inadequate glycemic control by diet and exercise: a randomized, double-blind, placebo-controlled, phase 3 trial. Diabetes Care. 2010; 33(10): 2217-2224

127. Nauck MA, Del Prato S, Meier JJ, et al. Dapagliflozin versus glipizide as add-on therapy in patients with type 2 diabetes who have inadequate glycemic control with metformin: a randomized, 52-week, double-blind, active-controlled noninferiority trial. Diabetes Care. 2011; 34(9): 2015-2022.

128. Wilding JP, Norwood P, T'joen C, et al. A study of dapagliflozin in patients with type 2 diabetes receiving high doses of insulin plus insulin sensitizers: applicability of a novel insulin-independent treatment. Diabetes Care. 2009; 32(9): 1656-1662.

129. Bristol-Myers Squibb A. U. S. Food and Drug Administration Endocrinologic \& Metabolic Advisory Committee Background Document: Dapagliflozin, BMS-512148, NDA202293. Princeton, NJ: Bristol-Myers Squibb. 2011; 1-224.

130. Pratley RE, Salsali A. Inhibition of DPP-4: a new therapeutic approach for the treatment of type 2 diabetes. Curr Med Res Opin. 2007; 23(4): 919-931.

131. Solun B, Marcoviciu D, Dicker D. Dipeptidyl peptidase- 4 inhibitors and their effects on the cardiovascular system. Curr Cardiol Rep. 2013; 15(8): 382.

132. Thornberry NA, Gallwitz B. Mechanism of action of inhibitors of dipeptidyl-peptidase-4 (DPP-4). Best PractRes Clin Endocrinol Metab. 2009; 23(4): 479-486.

133. Pan C, Wang X. Profile of vildagliptin in type 2 diabetes: efficacy, safety, and patient acceptability. Ther Clin Risk Manag. 2013; 9: 247-257.

134. Iwamoto Y, Tajima N, Kadowaki T, et al. Efficacy and safety of sitagliptin monotherapy compared with voglibose in Japanese patients with type 2 diabetes: a randomized, double-blind trial. Diabetes Obes Metab. 2010; 12(7): 613-622.

135. Maeda H, Kubota A, Kanamori A, et al. Long-term efficacy and safety of sitagliptin in the treatment of Japanese Type 2 diabetes (ASSET-K1) to a target of HbA1c <7\%. J Endocrinol Invest. 2013; 36(8): 568-573.

136. Petersen $\mathrm{AB}, \mathrm{Christensen} \mathrm{M}$. Clinical potential of lixisenatide once daily treatment for type 2 diabetes mellitus. Diabetes Metab Syndr Obes. 2013; 6: 217-231.

137. Briscoe CP, Tadayyon M, Andrews JL, et al. The orphan G protein-coupled receptor GPR40 is activated by medium and long chain fatty acids. J Biol Chem. 2003; 278(13): 11303-11311.

138. Itoh $\mathrm{Y}$, Kawamata $\mathrm{Y}$, Harada $\mathrm{M}$, et al. Free fatty acids regulate insulin secretion from pancreatic beta cells through GPR40. Nature.2003; 422 (6928):173-176.

139. Burant CF, Viswanathan P, Marcinak J, et al. TAK- 875 versus placebo or glimepiride in type 2 diabetes mellitus: a phase 2, randomised, double-blind, placebo-controlled trial. Lancet. 2012; 379(9824): 1403-1411.

140. Tanaka H, Yoshida S, Oshima H, et al. Chronic treatment with novel GPR40 agonists improve whole-body glucose metabolism based on the glucose-dependent insulin secretion. J Pharmacol Exp Ther. 2013; 346(3): 443-452.

141. Ghasemi A, Zahediasl S. Is nitric oxide a hormone? Iran Biomed J. 2011; 15 (3): 59-65.

142. Webb AJ, Patel N, Loukogeorgakis S, et al. Acute blood pressure lowering, vasoprotective, and antiplatelet properties of dietary nitrate via bioconversion to nitrite. Hypertension. 2008; 51(3): 784-790.

143. Weitzberg E, Lundberg JO. Dietary nitrate-a slow train coming. J Physiol. 2011; 589 (Pt 22): 5333-5334.

144. Carlström M, Larsen FJ, Nyström T, et al. Dietary inorganic nitrate reverses features of metabolic syndrome in endothelial nitric oxide synthase-deficient mice. Proc Natl Acad Sci USA. 2010; 107(41): 17716-17720.

145. El-Wakf AM, Hassan HA, El-said FG, et al. Hypothyroidism in male rats of different ages exposed to nitrate polluted drinking water. Res J Med Med Sci. 2009; 4(2): 160-164

146. Ghasemi A, Zahediasl S. Potential therapeutic effects of nitrate/nitrite and type 2 diabetes mellitus. Int J Endocrinol Metab. 2013; 11(2): 63-64.
147. Olefsky JM, Glass CK. Macrophages, inflammation, and insulin resistance. Annu Rev Physiol. 2010; 72: 219-246.

148. Zhao Y. Stem cell educator therapy and induction of immune balance. Curr Diab Rep. 2012; 12: 517-523.

149. Zhao Y, Jiang Z, Zhao T, et al. Reversal of type 1 diabetes via islet beta cell regeneration following immune modulation by cord blood-derived multipotent stem cells. BMC Med. 2012; 10: 3 .

150. Zhao $Y$, Jiang $Z$, Zhao $T$, et al. Targeting insulin resistance in type 2 diabetes via immune modulation of cord blood-derived multipotent stem cells (CB-SCs) in stem cell educator therapy: phase I/II clinical trial. BMC Med. 2013; 11: 160.

151. Donath MY, Shoelson SE. Type 2 diabetes as an inflammatory disease. Nat Rev Immunol. 2011; 11(2): 98-107.

152. Larsen CM, Faulenbach M, Vaag A, et al. Interleukin-1-receptor antagonist in type 2 diabetes mellitus. N Engl J Med. 2007; 356(15): 1517-1526.

153. Fleischman A, Shoelson SE, Bernier R, et al. Salsalate improves glycemia and inflammatory parameters in obese young adults. Diabetes Care. 2008; 31(2): 289-294.

154. Timper K, Donath MY. Diabetes mellitus type 2-the new face of an old lady. Swiss Med Wkly. 2012; 142: w13635.

155. Ceriello A, Testa R. Antioxidant anti-inflammatory treatment in type 2 diabetes. Diab Care. 2009; 32(2): S232-S236.

156. Rahimi R, Nikfar S, Larijani B, et al. A review on the role of antioxidants in the management of diabetes and its complications. Biomed Pharmacother. 2005; 59: 365-373

157. Gillies CL, Lambert PC, Abrams KR, et al. Different strategies for screening and prevention of type 2 diabetes in adults: cost effectiveness analysis. BMJ. 2008; 336(7654): 1180-1185.

158. Lindström J, Tuomilehto J. The diabetes risk score: a practical tool to predict type 2 diabetes risk. Diabetes Care. 2003; 26(3): 725-731.

159. Schulze MB, Hoffmann $\mathrm{K}$, Boeing $\mathrm{H}$, et al. An accurate risk score based on anthropometric, dietary, and lifestyle factors to predict the development of type 2 diabetes. Diabetes Care. 2007; 30(3): 510-515.

160. Gray LJ, Taub NA, Khunti K, et al. The Leicester Risk Assessment score for detecting undiagnosed Type 2 diabetes and impaired glucose regulation for use in a multiethnic UK setting. Diabet Med. 2010; 27(8): 887-895.

161. Hippisley-Cox J, Coupland C, Robson J, et al. Predicting risk of type 2 diabetes in England and Wales: prospective derivation and validation of ODScore. BMJ. 2009; 338: b880.

162. Schwarz PE, Li J, Bornstein SR. Screening for type 2 diabetes in primary care. BMJ. 2009; 338: b973.

163. Griffin SJ, Little PS, Hales CN, et al. Diabetes risk score: towards earlier detection of type 2 diabetes in general practice. Diabetes Metab Res Rev 2000; 16(3): 164-171.

164. Schwarz PE, Li J, Lindstrom J, et al. Tools for predicting the risk of type 2 diabetes in daily practice. Horm Metab Res. 2009; 41(2): 86-97.

165. Meisinger C, Strassburger K, Heier M, et al. Prevalence of undiagnosed diabetes and impaired glucose regulation in 35-59-year-old individuals in Southern Germany: the KORA F4 Study. Diabet Med. 2010; 27(3): 360-362.

166. Park PJ, Griffin SJ, Sargeant L, et al. The performance of a risk score in predicting undiagnosed hyperglycemia. Diabetes Care. 2002; 25(6): 984-988.

167. Abdul-Ghani MA, Lyssenko V, Tuomi T, et al. Fasting versus postload plasma glucose concentration and the risk for future type 2 diabetes: results from the Botnia Study. Diabetes Care. 2009; 32(2): 281-286.

168. Lorenzo C, Williams K, Hunt KJ et al. The National Cholesterol Education Program-Adult Treatment Panel III, International Diabetes Federation, and World Health Organization definitions of the metabolic syndrome as predictors of incident cardiovascular disease and diabetes. Diabetes Care. 2007; 30(1): $8-13$.

169. Abdul-Ghani MA, Abdul-Ghani T, Ali N, et al. One-hour plasma glucose concentration and the metabolic syndrome identify subjects at high risk for future type 2 diabetes. Diabetes Care. 2008; 31(8):1650-1655.

170. Schulze MB, Weikert C, Pischon T, Bergmann MM, et al. Use of multiple metabolic and genetic markers to improve the prediction of type 2 diabetes: the EPIC-Potsdam Study. Diabetes Care. 2009; 32(11): 2116-2119.

171. Chien K, Cai T, Hsu H, et al. A prediction model for type 2 diabetes risk among Chinese people. Diabetologia. 2009; 52(3): 443-450.

172. van Hoek M, Dehghan A, Witteman JC, et al. Predicting type 2 diabetes based on polymorphisms from genome-wide association studies: a population-based study. Diabetes. 2008; 57(11): 3122-3128.

173. Cornelis MC, Qi L, Zhang C, et al. Joint effects of common genetic variants on the risk for type 2 diabetes in U.S. men and women of European ancestry. Ann Intern Med. 2009; 150(8): 541-550.

174. Janssens AC, Aulchenko YS, Elefante S, et al. Predictive testing for complex diseases using multiple genes: fact or fiction? Genet Med. 2006; 8(7): 395-400.

175. Janssens AC, Moonesinghe R, Yang Q, et al. The impact of genotype frequencies on the clinical validity of genomic profiling for predicting common chronic diseases. Genet Med. 2007; 9(8): 528-535.

176. Blair SN. Physical inactivity: the biggest public health problem of the 21st century. Br J Sports Med. 2009; 43(1): 1-2.

177. Bassuk SS, Manson JE. Epidemiological evidence for the role of physical activity in reducing risk of type 2 diabetes and cardiovascular disease. J Appl Physiol (1985). 2005; 99(3): 1193-1204.

178. Yates T, Davies M, Gorely T, et al. Effectiveness of a pragmatic education program designed to promote walking activity in individuals with impaired 
glucose tolerance a randomized controlled trial. Diabetes Care. 2009; 32(8): 1404-1410.

179. Telford RD. Low physical activity and obesity: causes of chronic disease or simply predictors? Med Sci Sports Exerc. 2007; 39(8): 1233-1240.

180. Laaksonen DE, Lindström J, Lakka TA, et al. Physical activity in the prevention of type 2 diabetes: the Finnish diabetes prevention study. Diabetes. 2005; 54(1): 158-165.

181. van Dam RM, Rimm EB, Willett WC, et al. Dietary patterns and risk for type 2 diabetes mellitus in U.S. men. Ann Intern Med. 2002; 136(3): 201-209.

182. Aune D, Ursin G, Veierød MB. Meat consumption and the risk of type 2 diabetes: a systematic review and meta-analysis of cohort studies. Diabetologia. 2009; 52(11): 2277-2287

183. Hodge AM, English DR, O'Dea K, et al. Alcohol intake, consumption pattern and beverage type, and the risk of Type 2 diabetes. Diabet Med. 2006; 23(6): 690-697.

184. Ramachandran A, Snehalatha C, Mary S, et al. The Indian Diabetes Prevention Programme shows that lifestyle modification and metformin prevent type 2 diabetes in Asian Indian subjects with impaired glucose tolerance (IDPP-1). Diabetologia. 2006; 49(2): 289-297.

185. Kosaka K, Noda M, Kuzuya T. Prevention of type 2 diabetes by lifestyle intervention: a Japanese trial in IGT males. Diabetes Res Clin Pract. 2005; 67(2): 152-162.

186. Pan XR, Li GW, Hu YH, et al. Effects of diet and exercise in preventing NIDDM in people with impaired glucose tolerance. The Da Qing IGT and Diabetes Study. Diabetes Care. 1997; 20(4): 537-544.

187. Lindström J, Eriksson JG, Valle TT, et al. Prevention of diabetes mellitus in subjects with impaired glucose tolerance in the Finnish Diabetes Prevention Study: results from a randomized clinical trial. J Am Soc Nephrol. 2003; 14 (7 Suppl 2): S108-S113

188. Diabetes Prevention Program (DPP) Research Group. The Diabetes Prevention Program (DPP): description of lifestyle intervention. Diabetes Care. 2002; 25(12): 2165-2171.

189. Salas-Salvadó J, Bulló M, Babio N, et al. Reduction in the incidence of type 2 diabetes with the Mediterranean diet: results of the PREDIMED-Reus nutrition intervention randomized trial. Diabetes Care. 2011; 34(1): 14-19.

190. Gillies CL, Abrams KR, Lambert PC, et al. Pharmacological and lifestyle interventions to prevent or delay type 2 diabetes in people with impaired glucose tolerance: systematic review and meta-analysis. BMJ. 2007; 334(7588): 299

191. Tuomilehto J, Lindström J, Eriksson JG, et al. Prevention of type 2 diabetes mellitus by changes in lifestyle among subjects with impaired glucose tolerance. N Engl J Med. 2001; 344(18): 1343-1350.

192. Vermunt PW, Milder IE, Wielaard F, et al. Behavior change in a lifestyle intervention for type 2 diabetes prevention in Dutch primary care: opportunities for intervention content. BMC Fam Pract. 2013; 14(1): 78

193. Shaw K, O'Rourke P, Del Mar C, et al. Psychological interventions for overweight or obesity. Cochrane Database Syst Rev. 2005; (2): CD003818.

194. Paulweber B,Valensi P, Lindström J, et al. A European evidence-based guideline for the prevention of type 2 diabetes. Horm Metab Res. 2010; 42 (Suppl 1): S3-S36.

195. Greaves CJ, Sheppard KE, Abraham C, et al. Systematic review of reviews of intervention components associated with increased effectiveness in dietary and physical activity interventions. BMC Public Health. 2011; 11: 119.

196. Danaei G, Finucane MM, Lu Y, et al. National, regional, and global trends in fasting plasma glucose and diabetes prevalence since 1980: systematic analysis of health examination surveys and epidemiological studies with 370 country-years and 27 million participants. Lancet. 2011; 378(9785): 31-40.

197. Kershaw EE, Chua SC, Williams JA, et al. Molecular mapping of SSRs for Pgm1 and C8b in the vicinity of the rat fatty locus. Genomics. 1995; 27(1): 149-154.

198. Cornier MA, Donahoo WT, Pereira R, et al. Insulin sensitivity determines the effectiveness of dietary macronutrient composition on weight loss in obese women. Obes Res. 2005; 13(4):703-709.

199. Lindström J, Ilanne-Parikka P, Peltonen M, et al. Sustained reduction in the incidence of type 2 diabetes by lifestyle intervention: follow-up of the Finnish Diabetes Prevention Study. Lancet. 2006; 368(9548): 1673-1679.

200. Hamman RF, Wing RR, Edelstein SL, et al. Effect of weight loss with lifestyle intervention on risk of diabetes. Diabetes Care. 2006; 29(9): 2102-2107.

201. Kulzer B, Hermanns N, Gorges D, et al. Prevention of diabetes self-management program (PREDIAS): effects on weight, metabolic risk factors, and behavioral outcomes. Diabetes Care. 2009; 32(7): 1143-1146.

202. Mozaffarian D, Hao T, Rimm EB, et al. Changes in diet and lifestyle and long-term weight gain in women and men. N Engl J Med. 2011; 364(25): 2392-2404.

\section{Author biography}

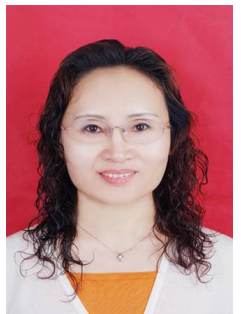

Dr. Yanling $\mathbf{W u}$ is a professor in Molecular Immunology and now heads the Cellular and Molecular Immunology Research Group. She received Master and Doctoral degrees in Applied Life Science in 2003 and in Medicine Science in 2006, respectively, from Tohoku University, Japan. After that, she entered to Professor Minato's group of School of Medicine, Kyoto University, Japan, as a senior researcher working in the field of molecular immunology. Her current researches focus on understanding the molecular mechanisms of gene regulation related to diseases by immune inhibitory receptors. Dr. Wu have given oral presentations in international conferences and published related papers.

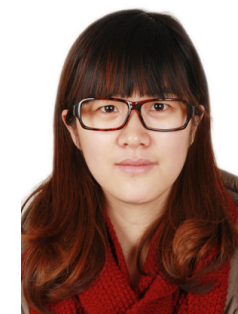

Yanping Ding received her bachelor's degree in biological sciences from Zhejiang University of Chinese Traditional Medicine, China. Since graduation, she has been working in Zhejiang Center of Disease Control and Prevention, China. Her research mainly focuses on the field of Molecular Immunology under the guidance of Prof. Yanling Wu.

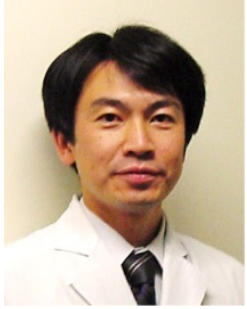

Yoshimasa Tanaka received his Ph. D in Hokkaido University Graduate School of Agriculture with a specialization in Enzymology and Biochemistry. After graduation, he continued his research in the field of Immunobiology. Since 2008, he is an associate professor and works in the Center for Innovation in Immunoregulative Immunology and Therapeutics that belongs to the Kyoto University Graduate School of Medicine. 


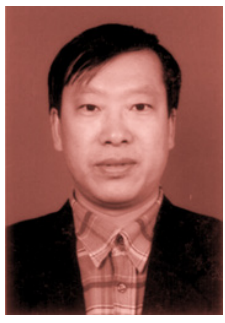

with 25 years of research and Zhang earned his doctorate degree in Bioorganic Chemistry from East China University of Science and Technology, China. Then, he entered Professor Ohrui's Lab of Tohoku University, Japan, working in the field of molecular recognition as a JSPS postdoctoral fellow. After that, he moved to Kyoto University, Japan, to join Professor Sugiyama's Chemical Biology group as a COE and JST research fellow working on biology and chemistry of polyamide-nucleic acids interaction. Now, Dr. Zhang has a special interest in elucidating the gene regulation mechanisms with small organic molecules and the development of gene-targeted drug. His group formed in 2008 and established an extremely fruitful collaboration with Prof. Sugiyama's Group in order to better pursue aspects of gene-targeted drug research. To date, Dr. Zhang has published better papers as the first/corresponding author in excellent Journals including JACS, JASN, ChemBioChem, Chem \& Biol, ChemMedChem, Int J Biol Sci etc. 